\title{
MANUEL REVUELTA. PALENTINO UNIVERSAL, HISTORIADOR ARRAIGADO EN SU TIERRA NATAL
}

\author{
EUSEBIO GIL CORIA, SJ ${ }^{1}$
}

RESUMEN: El Profesor Manuel Revuelta mantuvo como una de sus especialidades la historia de Palencia. Prácticamente toda su producción histórica sobre Palencia es ocasional, producida en intervalos de la labor primordial suya de historiador. Son estudios de investigación o de divulgación. En conjunto ofrecen un panorama esclarecedor de determinadas épocas y circunstancias de la vida de Palencia. Ordeno el conjunto de estos trabajos en: 1. Los dedicados a su villa natal. 2. Los dedicados a la provincia. 3. Los dedicados a la Iglesia de Palencia. 4. Una exposición del libro que es como el legado que el autor deja de su obra de historiador de Palencia.

PALABRAS CLAVE: Liberales; conservadores; anticlericalismo; clericalismo; desamortización; exclaustración.

\section{Manuel Revuelta. Universal palencian, historian rooted in his homeland}

ABstRact: Professor Manuel Revuelta kept the history of Palencia as one of his fields of specialty. Virtually all of his historical production on Palencia is occasional, produced at intervals of his primary work as a historian. These are research or outreach studies. Together they offer an enlightening picture of certain times and circumstances of life in Palencia. I have ordered all these works in: 1. Those dedicated to his hometown. 2. Those dedicated to the province. 3. Those dedicated to the Church of Palencia. 4. An exhibition of the book that is the legacy the author leaves from his work as historian of Palencia.

KEY WORDS: Liberals; conservatives; anti-clericalism; clericalism; disentailment; secularization.

\footnotetext{
1 Profesor jubilado Universidad Pontificia Comillas. Correo electrónico: ecoria@ comillas.edu.
} 
El Profesor Manuel Revuelta mantuvo como una de sus especialidades ocuparse de la Historia de Palencia ${ }^{2}$. Fue ésta una dedicación suya muy temprana. Estrenaba su docencia de Historia en la Universidad Pontificia Comillas en el curso 1968-69, a la vez que se ocupaba en la redacción de su tesis doctoral. En los tiempos libres que dejaban sus dedicaciones primordiales, comienza a investigar sobre Palencia.

Podemos decir que prácticamente toda la producción histórica de Manuel Revuelta sobre Palencia es ocasional y miscelánea, producida a intervalos de la labor histórica primordial que traía entre manos. Lo que no quiere decir que sea un producto de menor categoría. Sean estudios de investigación o de divulgación, entran dentro de la categoría de obras notables que ofrecen en conjunto un panorama esclarecedor de determinadas épocas y circunstancias de la historia de Palencia. Quien nos ofrece esa visión del pasado no esconde que lo describe con una mirada humana alumbrada por la fe de cristiano comprometido.

He ordenado el conjunto de estos trabajos sobre la historia de Palencia atendiendo a su contenido en: 1. Los dedicados a su villa natal. 2. Los dedicados a la provincia de Palencia. 3. Los dedicados a la Iglesia de Palencia. Cierro con una exposición del libro Historia y camino en tierras palentinas que es como el legado que ha dejado Manuel Revuelta de su obra de historiador de Palencia.

\section{UNA VILLA EN EL CAMINO DE EUROPA}

El primer trabajo que emprende Manuel Revuelta sobre su tierra tiene como objeto su villa natal Población de Campos. Esta villa había estado bajo la jurisdicción de la Orden de Malta durante casi siete siglos. Consultando en los archivos los documentos de la Orden, redacta un artículo que envía a un canónigo palentino, uno de los creadores de la Institución académica de Historia, Letras y Bellas Artes de la ciudad, que lleva el nombre Tello Téllez de Meneses. Al poco tiempo aparecía publicado el artículo en el n. ${ }^{\circ} 32$ de la publicación periódica de la Institución (Revuelta González, 1971). Dada la favorable acogida, envía un segundo artículo sobre la ermita de su pueblo, que aparece en la misma publicación periódica en 1973 (Revuelta González, 1973).

2 Pérez García, A. (2019). P. Manuel Revuelta González, Miscelánea Comillas 77, 254. 
El primer artículo enviado por Manuel Revuelta es un relato de las peripecias de la Orden Militar de San Juan (orden de Malta) en la vida del territorio de una de las tres bailías que el Gran Priorato de la Orden poseía en Castilla y León, la llamada la bailía de «Las Nueve Villas de Campos», de la que Población era algo así como la capital del territorio administrado por la bailía. La bailía era una unidad administrativa territorial de rango especial dentro del gobierno y administración de los bienes de la Orden.

La Orden de San Juan aparece en la España medieval casi en sus comienzos, debido al padrinazgo del rey Alfonso VII, su gran protector. Se sabe que el 24 de junio de 1140 Alfonso VII otorga al Maestre del hospital de San Juan de Salamanca la villa de Población. Teniendo en cuenta los documentos del siglo XVI sobre la bailía, parece que se trataba de una concesión del dominio señorial sobre toda la villa, lo que implicaba una situación de vasallaje de los vecinos hacia la Orden, además de la entrega en dominio directo, si no de todos, al menos de los bienes que el monarca tenía en aquel pueblo.

La jurisdicción de la Orden se fue ampliando al irse acogiendo a ella varios pueblos y por adquisición de bienes por la misma Orden. Por una bula que el Papa Clemente IV, como protector y jefe supremo de la Orden, dirige el 15 de febrero de 1267 al rey Alfonso el Sabio, con ocasión de un conflicto entre el infante don Felipe hermano del rey y la bailía de Población, se puede inferir que la bailía de Población estaba del todo organizada en su configuración territorial con notable aporte de ingresos empleados en la asistencia a los necesitados y en defensa de los cristianos de Tierra Santa. Logró su plena madurez en el siglo XII. Las ermitas de la bailía, que aún se conservan, se edificaron en el último tercio del siglo XII y el primero del siglo XIII. Ellas dan señal de una dedicación espiritual y cultural que no aparece en el siglo XVI.

Los dominios de la bailía se extendían a 51 pueblos: 37 en la zona sur, casi todos en la parte oriental de la tierra de Campos y 14 en la zona norte, de montaña. En la zona sur poseía grandes posesiones y derechos señoriales sin actividad pastoral o espiritual. La zona norte apenas tenía lo justo para la subsistencia de los priores y capellanes que atendían a las iglesias sobre las que la Orden ejercía su jurisdicción espiritual.

Las fuentes documentales de los siglos XVI, XVII y XVIII sobre la bailía, conservadas en el Archivo Histórico Nacional, son suficientes para hacerse una imagen consistente del gobierno de la Orden en este periodo, en lo que concierne a las jurisdicciones señorial y eclesiástica y a sus posesiones. El bailío o comendador es un religioso que gobierna la bailía conforme a unos estatutos, con jurisdicción civil y criminal sobre algunos lugares, que en esta época existían solo en tres sitios, uno de ellos Población. El bailío nunca residió en el bailiaje. Nombraba un gobernador que residía en Población. Los 
bailíos eran personas nobles o beneméritas de la Orden. El Gran Maestre de la Orden nombraba al bailío, que generalmente residía en la Corte o ejercía otros cargos. Podríamos decir que su único interés por la bailía era el cobro de las rentas que ejecutaban los administradores.

La Orden de San Juan tenía la jurisdicción espiritual sobre diferentes lugares, los Prioratos, que estaban exentos de la jurisdicción episcopal y dependían del Gran Prior con la Santa Asamblea. En el territorio de la bailía de Población había cuatro prioratos en la zona norte. En Población existió un priorato, en la Iglesia de San Pedro, que en el siglo XVI quedó vacante y abandonado. Los cuatro priores del norte ejercían como párrocos y además atendían algunas ermitas o iglesias anejas. La propiedad de estas iglesias la tenía el bailío sobre el que recaían sus cargas, que satisfacía con las rentas de la bailía y con los diezmos de Población y de los prioratos del norte. El Gran Prior concedía la colación canónica de los priores-párrocos. Él ordenaba en ocasiones las visitas nombrando un visitador. Estas visitas eran casi el único recurso de base espiritual y coactiva que la Orden tenía para estimular en sus deberes pastorales a unos priores que vivían muy alejados de sus superiores, revisar el estado de los edificios y recordar a los bailíos que su bailía no era solo una fuente de rentas.

Con la caída de la isla de Malta en manos de Napoleón en 1978, comienza la desintegración de la Orden. Carlos IV incorporó a la Corona, en 1802, el Maestrazgo de la Orden en España. Esto significaba que los recursos vacantes de las encomiendas quedaban a disposición del rey. Las Cortes de Cádiz declaran nacionales los bienes de las encomiendas en 1813. El decreto estuvo en vigencia o en suspenso, siguiendo los vaivenes del reinado de Fernando VII. Lo primero que hizo el gobierno, a comienzos de enero de 1834, fue declarar la competencia del Ministerio de Hacienda en la administración de las encomiendas. Por fin, el real decreto de 1 de mayo de 1848 ponía en venta los bienes raíces y demás acciones de las encomiendas de la Orden de San Juan.

Manuel Revuelta concluye con un duro juicio acerca del destino de la Orden de San Juan en España. Considera su supresión una muerte natural. Estaba, según él, carcomida. La orden había nacido siguiendo el consejo evangélico de hospedar a los necesitados y enfermos y acoger a los peregrinos. A partir del siglo XVI no se tienen noticias de que la Orden cumpliera con este compromiso. El carácter militar, por otro lado, había perdido definitivamente su sentido. El bailío solo vivía para lograr ser señor de una bailía o de una encomienda. Desde la dinastía de los Borbones, los Grandes Prioratos eran patrimonio hereditario de los infantes reales.

El artículo de la ermita de Nuestra Señora del Socorro es un estudio que Revuelta oportunamente envía también a Palencia aprovechando que está 
siendo restaurado un resto de lo que fue, en un principio, el edificio de la iglesia titular del Priorato de San Pedro, que perteneció a la Orden de San Juan en Población. Siguiendo las etapas sucesivas de erosión de la iglesia, el autor nos describe el proceso de descomposición del Priorato de la villa. Casi en las fechas en que los Reyes Católicos dan fin a la Reconquista con la toma de Granada, Frey Rodrigo de Valderrábanos recibía el Priorato de San Pedro. No residió en la Villa. Arrendaba el beneficio a administradores y su interés exclusivo era cobrar las rentas. Nunca nombró Capellán sustituto y exigía a sus arrendatarios que contrataran a su costa un sacerdote que dijera tres misas a la semana. Se terminó por asignar este servicio a los clérigos de la parroquia de la villa, quienes al fin abandonaron el servicio. Nada hizo para mantener en buen estado los edificios de su Priorato. En 1519 fue nombrado un visitador, que comprobó el estado de San Pedro en total abandono. Se hicieron las reparaciones más urgentes de retejado y limpieza.

Sin embargo, en 1619 se encuentra la iglesia de San Pedro con las cuatro paredes al aire. Queda la capilla de Nuestra Señora, donde se dice misa. Nada de extrañar, pues ya hacía tiempo que no se nombraba prior. Los Visitadores de 1627 encuentran la iglesia en total ruina. El costo de la reapertura era de tal envergadura que solo se arreglaron los desperfectos de la capilla de la Virgen y se recuperaron los objetos de culto que habían sido sustraídos. En el siglo siguiente la iglesia de San Pedro ya no existe. Queda la capilla arreglada a la que el pueblo llamaba la ermita del Corro, título que derivó, debido a la devoción del pueblo, en ermita del Socorro. Esta devoción del pueblo mantuvo a la ermita atendida durante las peripecias del siglo XIX. Los pastores del pueblo tomaron como patrona a la «Virgen del Socorro» en 1899. A ellos se debe que la ermita no desapareciera.

Cierra el artículo Manuel Revuelta con una acertada conclusión sobre el sentido de la moderna restauración resaltando el apoyo prestado por el pueblo, la diócesis y el erario común. Es un mensaje de espiritualidad y de esperanza para una sociedad que olvida los pueblos debilitados por la despoblación, pueblos que se apoyan en los vestigios de lo mejor de su pasado. Lo hace con un lenguaje vibrante, con tonos en algún momento tópicos: el mensaje de esas obras «tiene un valor eterno e imperecedero: conservar el tesoro de la fe religiosa de los padres, y exaltar los valores espirituales del hombre» (Revuelta González, 1971, p. 274). 


\section{PALENCIA, PROVINCIA DE CASTILLA Y DE ESPAÑA}

En el mismo año que Manuel Revuelta publicaba el artículo sobre la ermita del Socorro, aparecía publicada su tesis doctoral: Política religiosa de los liberales en el siglo XIX. Trienio constitucional (1833-1940). Los dos libros ofrecen sendas síntesis históricas de dos momentos convulsos de las relaciones entre el Estado y la Iglesia en la España de la primera mitad del siglo XIX. Llamó la atención de los especialistas y entendidos en historia la forma de escribir historia de Manuel Revuelta. El estilo de escritura del autor convierte la lectura de sus obras en contemplación de escenas vivas, ofreciendo al lector ocasión de reflexionar sobre ellas y emitir sus propios juicios. Hay ponderación y cuidado en sus asertos, siempre apoyados en la ajustada valoración de datos, lecturas y comunicación con especialistas, unido a una cálida y comprensiva mirada humana. La segunda obra La exclaustración (1833-1840), publicada tres años después, es un modelo de hacer historia de un drama social y religioso con ánimo sereno y a la vez dolorido, pero no obnubilado por mirada oblicua. «Se consideró a esta obra fundamental e imprescindible». El mejor juicio de la obra lo da el autor en el prólogo a su segunda edición de 2010: «Se trata de un libro de juventud... Hoy habríamos matizado algunos juicios demasiado rotundos, habríamos suavizado el tono moralizante de algunas páginas, nos habríamos mostrado más comprensivos con unos y con otros, incluso habríamos corregido el estilo vehemente de algunos pasajes, utilizando una redacción más sobria. Pero es mejor dejar el libro - en su contenido y en su estilo- tal como salió. Es como un retrato de los años pasados»(Revuelta González, 2010, p. 12).

De una conferencia que Manuel Revuelta tuvo en Aguilar de Campoo en 1981 y en la Diputación de Palencia el 3 de agosto del mismo año, nació el libro Orígenes históricos de la constitución de la Provincia de Palencia, publicado por la Diputación Provincial en 1981. En cincuenta páginas expone magistralmente la difícil gestación de una provincia desde que en 1804 Carlos IV suprimió la antigua provincia de Toro, y asignó a Palencia los partidos de Carrión y Reinosa.

Concisamente se nos exponen los seis modelos de provincia que se sucedieron desde 1802 a 1833 siguiendo los vaivenes de las contiendas políticas y militares entre patriotas y afrancesados, absolutistas y liberales, éstos divididos en moderados y progresistas.

El gobierno de José Bonaparte es el primero que impone en el suelo español la constitución de Bayona de 1808, que institucionaliza un régimen monárquico autoritario, que recoge la libertad personal de derechos de todos los españoles, pero, aunque reconoce la división de poderes, el eje de todo 
el sistema es la corona. En 1910 publicaba José I una división del territorio nacional en departamentos que denominó prefecturas. Una de ellas la prefectura de Palencia cuyos límites reducían la provincia ampliada, pero respondía a criterios racionales geográficos y administrativos.

La Constitución de 1812 de las Cortes de Cádiz proclama al pueblo soberano e instituye la división de poderes. En cuanto a la administración territorial, la constitución apoya el gobierno político de las provincias en tres instituciones: el Ministerio del Interior, el gobernador civil y las diputaciones provinciales. Rápidamente establece en las provincias existentes al Gobernador Civil y la Diputación. Las Cortes ordenaron a la Regencia que reuniera datos para una nueva demarcación provincial. Recibían el expediente en enero de 1914. Nombraron una comisión que elaborara una división del territorio, pero cuando en abril, el consejo de Estado daba sus últimas observaciones al expediente, el 4 de mayo Fernando VII firma un decreto que declara nulo lo hecho por la Cortes, y proclama la monarquía absoluta en Madrid el día 12 inaugurando del sexenio absolutista. Durante el sexenio la provincia de Palencia permanece con la demarcación de 1808.

Con el trienio liberal en 1820, vuelve la provincia de Palencia a tener gobernador civil y diputación provincial con dos diputados a Cortes. El gobierno crea una comisión facultativa que diseñe el territorio nacional. Diputación y ayuntamiento de Palencia envían sus representantes a esa comisión. El ayuntamiento, por su parte, envía en febrero de 1821 dos agentes a Madrid. Constatan que el plan de división en provincias ha suprimido la provincia de Palencia. En 1821, se inaugura la legislatura ordinaria desde el 1 de marzo al 21 de julio. El gobierno presentó el plan de división. Las Cortes nombran una comisión especial que se encargue del diseño. Ayuntamiento y Diputación de Palencia envían alegaciones a esta comisión. En ellas insistían en la estrecha vinculación de las diversas regiones de la provincia. La comisión tomó muy en serio sus argumentos. En el dictamen del proyecto de ley firmado el 21 de junio de 1821, los criterios seguidos para la división en provincias fueron: la población, la extensión, la topografía. Las nuevas provincias con sus capitales eran 51. Entre ellas aparecía «Palencia, capital Palencia». La discusión sobre Palencia se tiene el 13 de octubre. El diputado vallisoletano Francisco Ramonet impugnó de manera torpe y presuntuosa que se concediera provincia a Palencia. La defensa del presidente de la comisión Diego Clemencín se centró en las ventajas de las provincias pequeñas, pues facilitan eficacia en el gobierno. El diputado palentino Santiago Calderón expuso las características y capacidades de la provincia y el otro diputado Manuel Fraile, obispo de Sigüenza, acentuó que nadie hubiera reclamado contra Palencia, a no ser los interesados ciudadanos de Valladolid. Aprobada la provincia de 
Palencia, siguió la discusión de los límites. El partido de Reinosa pasaba a la provincia de Santander. Por parte de Valladolid se exigía que pasasen a su provincia los poblados del Cerrato. En las variaciones definitivas presentadas por la comisión se mantiene esta exigencia de Valladolid, pero quedaba como provisional, sujeta a posibles variaciones.

En 1833, «la década ominosa» restablece las antiguas provincias. En la regencia de María Cristina, el decreto de 30 de noviembre de 1833 decide la nueva división de provincias que será definitiva. El responsable de la demarcación fue el ministro de fomento Javier de Burgos, hombre liberal, al que le sirvió de guía la división de 1822. Confirmó la separación de Reinosa en el norte y devolvió a Palencia siete pueblos del partido de Aguilar de Campoo que en 1822 habían pasado a Santander. En el Cerrato trazó una línea transversal, al sur de la cual siete pueblos del valle de la Esgueva, que habían sido palentinos, pasaron a Valladolid. En el extremo suroccidental pasaron a Valladolid cinco pueblos de los Montes de Torozos y seis de la Tierra de Campos.

Manuel Revuelta añade un apéndice documental. En él reproduce, del nomenclátor de 1879 del Conde de Floridablanca, las poblaciones de las provincias de Toro y Palencia. Y sobre todo añade seis documentos interesantísimos para calibrar cómo se sienten comunidad los habitantes unidos por el territorio que habitan, debido a sus ideales e intereses y a su historia.

Aguilar de Campoo estaba unido, en el recuerdo y en los más íntimos sentimientos de Manuel Revuelta, no a su labor de conferenciante e historiador, sino a la amistad que mantuvo, desde su infancia en el Colegio San José de Valladolid, con un natural de esa villa, Gregorio Ruiz. Ambos comenzaron el bachillerato, en el año 1946 y allí comenzó su amistad y a la vez su competición por la excelencia en los estudios con la misma intensidad que crecía la amistad entre ellos. Ambos poseyeron una inteligencia superior, Manuel Revuelta más para las letras, Gregorio Ruiz (Goyo, como se le llamó siempre) especialmente dotado para las matemáticas y las lenguas. Si Goyo recibió el título de «brigadier», la máxima dignidad del colegio, en el último curso de bachillerato, Manuel Revuelta le arrebató el premio extraordinario en la nota de reválida por medio punto. Juntos entraron en el año 1953 en el noviciado jesuita de Salamanca, donde después de dos años de noviciado, siguieron juntos tres cursos de humanidades, tres años de filosofía en Comillas (Cantabria) de 1958 a 1961. Goyo siguió después un año como enseñante en Comillas, mientras Manuel Revuelta comenzaba sus estudios de historia en la Universidad de Santiago de Compostela, donde logró la licenciatura con la máxima calificación. Como estudiantes de teología coincidieron ambos en la Facultad de Sankt Georgen de Frankfurt, donde se ordenaron de sacerdotes 
en julio de 1966. Vuelven ambos, después de tres años, a encontrarse de profesores en la Universidad Pontificia Comillas de Madrid desde 1969. Pero, en la noche del 29 de agosto de 1986, Goyo pierde la vida en accidente de tráfico. En el libro-memoria Encuentro con Goyo Ruiz, donde un grupo de amigos recogieron las palabras que pronunciaron en su recuerdo el 5 de octubre en Aguilar, las páginas escritas sobre su paisano por su amigo Manolo, «Recuerdos de juventud junto a Goyo», se cierran evocando su figura, «una fuente que derramaba sobre los demás lo mejor de sí mismo, una roca inconmovible por su fidelidad a los valores esenciales, gran amigo fiel a sus raíces, fiel a sí mismo y a Dios» (Ruiz, 1987, p. 22).

Frómista se encuentra en el camino francés de Santiago, en el cruce de la vía que baja de Cantabria a Madrid. A cuatro kilómetros al oeste por el camino de Santiago se encuentra Población de Campos. Frómista es una villa que seguramente se creó en la tercera etapa de la repoblación de la tierra de Campos a finales del siglo IX. Lugar de señorío, ya en el siglo XI, Frómista era un pueblo importante abierto a las corrientes espirituales de la Europa cristiana.

En ella vivió Muniadona Mayor, hija del conde Sancho García de Castilla, viuda de Sancho III de Navarra, fundadora del monasterio de San Martín de Tours con su iglesia. Alrededor del monasterio había ido surgiendo un barrio. En su testamento de 1066, la reina deja la mayoría de su herencia al monasterio, el barrio, sus viñas y tierras, varias posesiones en villas cercanas, la tercera parte de los diezmos de Frómista y Población. De los bienes en prestimonio que tenía en Asturias, destina una parte al lugar de su sepultura ${ }^{3}$, otra para el sustento de los sirvientes clérigos y laicos de San Martín y otra para que los monjes del monasterio ofrezcan sufragios por su alma.

Lo que a Manuel Revuelta le interesa enseñar es que «el pueblo que hoy llamamos Frómista estaba formado (durante varios siglos) por dos comunidades contiguas distintas, con dos jurisdicciones y concejos distintos: uno era la villa de Frómista... y el otro era el barrio de San Martín... Cuando Frómista reciba más adelante un señor, esta villa y el barrio contiguo tendrán dos gobernantes y jurisdicciones distintas: la villa será un señorío secular y el barrio un señorío eclesiástico o abadengo» (Revuelta González, 1987, p. 38). Esto estudia en la primera parte.

A comienzos del siglo XII en el año 1118, la reina Urraca, hija de Alfonso VI, dona el monasterio de San Martín con todos sus bienes y derechos al monasterio de San Zoilo de Carrión de los Condes que, desde el año 1076, se

\footnotetext{
3 El autor indica - que desconocemos-. El sepulcro de Muniadona Mayor se encuentra en el monasterio San Salvador de Oña (Burgos). «Quandoque bonus dormitat Homerus».
} 
regía por la Orden de Cluny. En este momento lo regentaba el abad Esteban, al que la reina llama «fidelissimo amico meo». El monasterio de San Martín se convierte en priorato.

Esta subordinación trajo consigo sus pleitos. Manuel Revuelta se demora en el pleito que mantuvo la fuerte personalidad autoritaria del obispo don Tello Téllez de Meneses con el monasterio de Frómista acerca de jurisdicciones. El priorato de san Martín estaba exento de la jurisdicción episcopal. El abad de Carrión cobraba los diezmos, visitaba la iglesia, nombraba y gobernaba los clérigos y sirvientes. Ocho años duró el pleito, de 1220 a 1228. El litigio terminó en un acuerdo por el que el obispo era quien aprobaba la colación canónica de los clérigos que le presentaba el abad de Carrión, y a quien le competía la visita y corrección de los clérigos y feligreses. El abad visitaba la iglesia y constataba el orden de la misma, disponía del empleo de los bienes de fábrica, de las limosnas y sepulturas. El obispo Tello Téllez fue un gran prelado y gran señor. Pertenecía a una de las más poderosas familias de la Tierra de Campos. Estudió en la escuela episcopal que había abierto en Palencia el obispo Arderico a la que había traído de Francia algunos maestros. Con él fueron condiscípulos Domingo de Guzmán y el canónigo Pedro González Telmo, el san Telmo de Frómista. Gran canonista y teólogo estimado por el Papa Inocencio III, don Tello destinó todos los recursos de su fortuna y muchos de su diócesis a convertir la escuela episcopal de Palencia en la primera Universidad de España. En 1215 asistió al IV Concilio de Letrán. El Papa Honorio III le enviaba la bula de la consagración de la catedral románica de Palencia el 23 de marzo de 1219.

La villa de Frómista, que debió de ser de realengo, aparece a finales del siglo XIII como villa de señorío. El barrio de San Martín seguía como priorato de Carrión. Pero, en 1291, un documento da noticia de que el barrio de San Martín estaba bajo la encomienda de la viuda del infante don Luis, hijo de Fernando III el Santo. Treinta años más tarde, en 1325, el señor de Frómista Juan Fernández Padilla paga al monasterio de San Zoilo 30.000 maravedís por el priorato de San Martín. El monasterio de Carrión ha tomado esta decisión apurado económicamente y apremiado por los prestamistas judíos. Iglesia y monasterio, junto con pequeños derechos, quedaban fuera del arriendo. Además, debían mantenerse los fueros y libertades de los vasallos de San Martín y nombrarse para los oficios a gente del barrio.

En los siglos XIV y XV, Frómista es uno más de los escenarios de la lucha de poder entre la vieja nobleza y la nueva estirpe de nobles proveniente de ricos señores, en los que encontró ayuda la corona en determinadas circunstancias. En 1327 era señor de Frómista un muchacho de diez años, sexto hijo del rey Alfonso XI y de Leonor de Guzmán, don Tello de Aguilar que, a partir 
de 1351, en que muere asesinada su madre por orden de su hermanastro Pedro I, tiene que vivir siempre huyendo. Cuando su hermano Enrique asesinó a don Pedro en 1369, Tello pudo recuperar su feudo de Frómista, pero murió al año siguiente. Enrique II concedió el señorío de la villa de Frómista en 1371, al Almirante Ferrán Sánchez de Tovar. El prior de Carrión le entregó la encomienda del barrio de San Martín. Tovar era un hombre duro y autoritario. Impuso fuertes tributos. Consideró el barrio de san Martín como perteneciente al señorío de Frómista. El señorío pasó a sus hijas. Éstas, al año, lo habían vendido al Adelantado Mayor de castilla Gómez Manrique, que ocupó la jurisdicción del barrio de San Martín. El monasterio puso pleito a Gómez Manrique en 1411, año en el que el Adelantado murió. Su hija heredera doña María Manrique, después de 16 años de pleitos consiguió el apoyo del Papa Martín V, y se llegó al acuerdo de Toro en 1427. El señorío de San Martín se entregaba a los señores de Frómista por el pago anual de 1.000 florines en concepto de censo perpetuo. Gómez de Benavides-Manrique de Rojas fue el siguiente señor de Frómista. Estaba entonces la villa en el momento de más esplendor. Contaba con una población cercana a los 4.000 habitantes. La expulsión de los judíos en 1492 supuso el comienzo del descenso demográfico y económico de Frómista.

La Frómista del siglo XVIII era una población empobrecida. Contaba en 1752, cuando el marqués de la Ensenada confecciona su catastro, con unos 1.000 vecinos, con 219 casas habitables y 40 arruinadas. Quedaban cuatro parroquias, el hospital de Santiago y el de Los Palmeros, y unas pocas tiendas. Pertenecía entonces al marquesado de Frómista, del que la Real Hacienda mantenía en suspenso sus derechos señoriales.

En su territorio dominaban las tierras de secano. El 80\% de las mismas para cereal y un $10 \%$ de viñedo. Contaba con importante cabaña de ganado lanar, unas cuantas yeguas de crianza, bueyes y mulas para la labranza y cerdos para el consumo. No todas las tierras eran de igual calidad. Las de primera clase se sembraban dos años seguidos y el tercero quedaban en barbecho. Las de tierras de segunda clase ocupaban cinco veces más de extensión que las de primera clase. Los rendimientos lógicamente muy diferentes. Comparados rendimientos y precios: «la impresión general que produce la lectura del informe es, que Frómista era un pueblo decadente, dormido; como tantos otros de la España que los Ilustrados querían renovar».

Por eso los reformadores del siglo XVIII proyectaron el Canal de Castilla. En 1783 el canal llegaba a Frómista desde Alar del Rey, de donde arranca del río Pisuerga. Estaba concebido para el riego de los campos y el transporte de mercancías. En Frómista tuvieron que construir cuatro exclusas para salvar el desnivel del río de más de 14 metros. A pesar de los 
dos molinos construidos junto a la gran esclusa y otro en la esclusa 21 , de un almacén de granos y de dos batanes, la población solo contaba 1.480 vecinos en 1829. En 1865 llegaba a Frómista el ferrocarril, pero ni aun así despegó su vida. Revuelta, sin embargo, concluye con un augurio evocativo: "Frómista de los tres caminos: el de Santiago, el canal de Castilla y el ferrocarril del Norte. Tres caminos que representan tres grandes valores: la espiritualidad cristiana, el cultivo de la tierra y el progreso humano» (Revuelta González, 1987, p. 58).

Manuel Revuelta fue un gran historiador del siglo XIX español. En la celebración del cincuenta aniversario de la Institución Tello Téllez de Meneses publicó un interesante artículo sobre la recuperación de la conciencia artística en Palencia, en el que trata de esa progresiva recuperación desde mediados del siglo XIX a comienzos del siglo XX (Revuelta González, 1999).

Hacia finales del siglo XVIII España contaba con un patrimonio artístico casi intacto y bien conservado porque «se poseía» y se estimaba. Los primeros que describieron y valoraron los monumentos de arte fueron algunos ilustrados, que realizaron viajes para estudiarlos. De estos, Revuelta escoge a dos: el castellonense abate Antonio Ponz, que en el tomo XI de su Viaje de España o Cartas en que se da noticia de las cosas más apreciables y dignas de saberse que hay en ella, publicado en 1783, da cuenta de la abundancia del patrimonio artístico de Palencia y de sus pueblos, los conventos, las parroquias y los edificios se conservaban en uso y cuidado. Puede decirse que la descripción que hace de la ciudad se puede estimar como una guía artística de Palencia. Visitó los principales pueblos. En la provincia había además 46 conventos.

El segundo autor que ha dejado sus juicios y pareceres sobre Palencia y su provincia es Gaspar Melchor de Jovellanos en sus Diarios, que no fueron editados hasta 1915. El primer viaje de Jovellanos a la provincia de Palencia en 1791 fue para ver el canal y el segundo, en un viaje de ida y vuelta de Asturias a La Rioja en 1795.

Ambos, viajeros, hombres ilustrados muy de su tiempo, tenían su sensibilidad estética subyugada por el clasicismo. No comprendían el románico, y el gótico era para ellos la expresión de una época medieval de incultura e ignorancia. Jovellanos es todavía sensible a la esbeltez de los grandes templos góticos. En Palencia admiró la catedral, pero ignoró la iglesia de San Miguel y su esbelta torre. De San Martín de Frómista solo dice: «iglesia graciosa, al parecer del siglo XII».

La pérdida del aprecio por el arte no vino por los juicios de los eruditos. Vino más bien por los desastres de la guerra y las reformas de los gobiernos liberales, herederos de los prejuicios de los ilustrados contra el arte medieval. 
Está en primer lugar la guerra de la Independencia. Hubo edificios destruidos, expolio de obras de orfebrería para aprovechar su oro y plata, robos de esculturas y pinturas. La provincia de Palencia quedó desde 1808 ocupada por las tropas de José Bonaparte hasta 1813. El 18 de agosto de 1809, un real decreto suprime las órdenes religiosas de varones. Inmediatamente se hace un inventario de bienes de los monasterios y conventos, donde los militares franceses saquearon gran cantidad de orfebrería, de obras de arte y de bibliotecas; espolio en el que también tuvieron su parte las bandas de insurgentes españoles rebeldes.

Pero las grandes pérdidas del patrimonio artístico nacional se dieron en tiempos de paz, cuando se ejecutó la desamortización. Aunque hay que poner otra causa de la pérdida de conciencia artística, y es la incultura de los que se aprovecharon de la desamortización, que solo evaluaban de aquellos bienes el provecho material que les podían reportar.

En la segunda mitad del siglo XIX comienza a surgir la preocupación por la pérdida del patrimonio artístico. Las crónicas de viajeros que hablan de las bellezas desconocidas o abandonadas, la exaltación del arte medieval por los poetas románticos, los historiadores del arte medieval, las revistas ilustradas, las sociedades culturales como los ateneos, las asociaciones de excursionistas y un resurgir religioso crean un ambiente favorable a la captación y comprensión de la obra de arte.

En 1852 el menorquín José María Quadrado, un católico balmesiano romántico, visita Palencia y la provincia. En 1861 publica el tomo Recuerdos y bellezas de España. Valladolid. Palencia. Zamora. Es un libro en el que texto escrito por Quadrado y las litografías del barcelonés Francisco Javier Parcerisa, un pintor romántico, católico comprometido como Quadrado, intentan presentar la historia de España buscando en su pasado cultural los valores que el positivismo del siglo XVIII ponía en peligro. Un gran idealismo poético inspira las ilustraciones de Parcerisa, idealismo unido al rigor histórico de los textos de Quadrado. Esta obra supo interpretar el mensaje de armonía y orden que las iglesias románicas de los pueblos palentinos transmiten y el recogimiento a que invitan, al estar ensambladas con el entorno, y valorar la elevación del espíritu que suscitan los templos góticos.

En el sexenio revolucionario (1868-1874) se da una nueva desamortización, razonada por el ministro de Fomento Manuel Ruiz Zorrilla en que esas obras son bienes nacionales que pertenecen al pueblo, a la nación. En Palencia, el gobernador y el alcalde incautaron los bienes del cabildo catedralicio, tomaron posesión de la biblioteca, archivo y sala capitular, de la que sustrajeron 29 cuadros. De la provincia se llevaron en 1871 y 1872 al Museo Arqueológico de Madrid el sepulcro romano de Husillos del siglo II y gran 
parte de los capiteles del claustro del monasterio de Santa María la Real de Aguilar. En la ciudad se cometieron destrozos en el convento de Santa Clara. La Propaganda Católica denunció en un artículo tales atropellos, lo mismo hizo el obispo Juan Lozano Torreira.

El alavés Ricardo Becerro de Bengoa, intelectual polifacético y político liberal republicano, con una vastísima obra escrita, que residió en Palencia de 1870 a 1875 como catedrático de física y química, influyó decisivamente en la toma de conciencia artística con su Libro de Palencia, editado en 1874. Se trata de un libro de carácter divulgativo. En él recomienda la restauración de la iglesia de San Martín de Frómista y juzga «crimen artístico» el traslado de los capiteles del monasterio de Aguilar.

La restauración alfonsina coincide en Palencia con un plantel de personalidades que enriquecieron la vida pública. La fama del pintor de renombre José Casado del Alisal, la fundación del Ateneo Palentino en 1876, la reactivación de la Sociedad de Amigos del País, la Escuela de Artes y Oficios. La devolución de los bienes incautados a la Iglesia en 1868, crearon un ambiente distendido y colaborativo en el aprecio del arte. Entre 1893 y 1907, bajo el liderazgo del médico y antropólogo liberal Francisco Simón Nieto y del obispo don Enrique Almaraz, un grupo de personalidades eclesiásticas y de profesionales e intelectuales seglares coinciden en resaltar los valores culturales del pasado. Crearon una Comisión de Monumentos eficaz. Simón Nieto publica en 1894 la obra Los antiguos Campos Góticos. El obispo don Enrique Almaraz vivía la restauración y recuperación del arte cristiano como un deber en su labor de restaurar la vida cristiana de la diócesis. Costeó con su dinero la restauración de iglesias y estableció la asignatura de arqueología en el Seminario. Las peregrinaciones, organizadas en los años de cambio de siglo a santuarios y ermitas, para afirmar la defensa de la fe cristiana en la vida pública, ayudaron a conservar muchos de esos santuarios. La Sociedad Castellana de Excursiones creada en Valladolid en 1903, con su filial en Palencia, publicaba un Boletín, donde aparecieron artículos de historia de la provincia escritos por plumas de primer orden.

En 1992 Manuel Revuelta es invitado a dar un curso de postgrado en la Universidad Iberoamericana de México. Aprovechó la ocasión para completar las noticias sobre la familia Mier y Pesado, de antecedentes palentinos nacidos en la Pernía palentina, de la que había tenido conocimiento por un libro raro de la biblioteca de la Universidad Pontificia Comillas. Con lo vivido y recogido en México compuso el trabajo «Finanzas y poesía en México y $\mathrm{Pa}$ lencia a través de la familia Mier y Pesado», (Revuelta González, 2001) leído como discurso de apertura del Curso Académico 2000/2001 de la Institución Tello Téllez de Meneses de Palencia. 
En su investigación inicial, consultó el apellido Mier en los archivos de los pueblos de la Pernía. Logró una genealogía de Gregorio Mier y Terán, el financiero que nació en 1796, hijo de Antonio Mier Terán y Antonia Alonso Terán. En México, consultando diccionarios mexicanos, se entera de que a Isabel Pesado, esposa de Gregorio Mier y Terán y autora del libro raro, se la conocía sobre todo como una filántropa y benefactora que en 1907 hizo testamento en París, donde murió en 1913, y legó su gran fortuna y la heredada de su marido a obras sociales. Con su legado se estableció en México la Fundación Mier y Pesado, que actualmente mantiene cuatro instituciones: dos colegios, uno para niñas en Guadalupe, otro para niños en Coyoacán, además de dos casas de salud para ancianos, una en Tacubaya y otra en Orizaba, la ciudad donde Isabel nació.

Pero lo interesante de la labor investigadora de Revuelta en este trabajo está en la labor de campo, la visita a las obras asistenciales de la fundación. Visita Villa de Guadalupe. Allí le dan la dirección de doña Guadalupe Mondragón de Campos (doña Lupita), vocal del patronato de la fundación, sobrina de los fundadores. Esta dama vivía en la antigua casa solariega de la familia situada en Tacubaya. La casa está ahora convertida en un asilo de ancianos. Del manuscrito de documentos, que doña Lupita le permitió consultar, sacó Revuelta materia decisiva para la biografía de los tres financieros palentinos de México.

El primero, Antonio Alonso Terán. Nacido en Piedras Luengas (Palencia) en 1768, emigró a Nueva España en las postrimerías de la colonia. Hizo pronto fortuna en el comercio y se lanzó a la compra de fincas y haciendas y a los préstamos a interés. Eran los primeros años de la independencia de México. don Alonso hizo préstamos a los gobiernos de la República, convirtiéndose en el acreedor del Estado. Falleció en 1835.

Gregorio de Mier y Terán, sobrino de don Antonio, era el séptimo hijo de doce hermanos de una familia campesina de San Juan de Redondo (Palencia), nacido el 24 de abril de 1796. Emigra a México en 1818 con su esposa María de Celis, seguro del apoyo de su tío materno. Desde 1830 a 1869 en que muerte, Gregorio de Mier y Terán fue el personaje más importante de la economía mexicana. Todo su negocio se asentaba en los préstamos a interés garantizados con hipotecas de bienes rústicos y urbanos. Las haciendas que adquiría por vencimiento de los primeros préstamos las vendía o arrendaba para lograr dinero y hacer nuevos préstamos. Entre 1858 y 1863 hizo préstamos a los gobiernos, fueran conservadores o liberales. Así participó en los negocios de minas, ferrocarriles y telégrafos. Su hija mayor Luisa de Mier y Celis fue bisabuela del príncipe Rainiero de Mónaco. 
Antonio de Mier y Celis, hijo de Gregorio, prefirió disfrutar de la fortuna adquirida como gran señor que además logró título nobiliario. Nacido en 1834, se casa con Isabel Pesado en 1867. Intervino en la política con el partido conservador. Fue primer presidente del Banco Nacional de México, que nació de la fusión del Banco Nacional Mexicano con el Banco Mercantil. En 1885, al resentirse su salud, le recetaron tomar baños en Europa. El matrimonio fijó su residencia en Paris. Antonio ejerció funciones diplomáticas para su país. Su salud no mejoró y murió en Paris el 13 de diciembre de 1899. Hombre de gran cultura, dominaba varios idiomas. Fue un excelente diplomático para su país. Contribuyó a la reparación de la Basílica de Guadalupe con 100.000 pesos. Está enterrado en la cripta, bajo el altar mayor, donde también están enterrados sus padres.

Isabel Pesado de la Llave, poetisa y viajera era hija de don José Joaquín Pesado, hijo único nacido en San Agustín del Palmar, en 1801, de Domingo Pesado, gallego que se casó en Orizaba con Josefa Pérez Casado. Domingo se dedicó en su juventud a la política en el partido liberal, llegó a diputado y vicegobernador de Veracruz, ministro del Interior en 1818 y de Relaciones Exteriores en 1846. Gran periodista y literato terminó como periodista del partido conservador. Catedrático de literatura en la Universidad de México, fue el primer escritor mexicano correspondiente de la Real Academia Española. Se casó en 1822 con María de la Luz de la Llave, de la que tuvo nueve hijos, siendo Isabel la quinta. En su casa reunía una tertulia, en la que Isabel recitó sus primeros versos.

Nacida en Orizaba en 1832, Isabel se casó en 1868 con Antonio de Mier y Celis. En diciembre de 1869 les nació el único hijo, que murió a los tres días de su nacimiento. Para superar Isabel el abatimiento por la pérdida del hijo emprende la pareja, en 1870, un viaje de dos años por Europa. Desde finales de 1872 a principios de 1885 residen en México. Vuelven a Europa en un segundo y definitivo viaje. En 1899 Isabel enviudó y en 1904, con 72 años, enfermó de tifus y no llegó a recuperarse. En 1908 publicó su libro de poemas Dichas y penas, en edición privada, y en 1910 publicó Apuntes de viaje. Vivió estos últimos años con la nostalgia y el dolor de no poder volver a México.

Como poetisa, los tres ejes que motivan sus poesías son el afecto familiar, la fe religiosa y la emoción del paisaje. Las poesías más sentidas son las que escribe para su esposo. Su poesía está esperando un merecido estudio a fondo. La obra en prosa Apuntes de viaje interesa sobre todo por la larga duración del viaje de dos años y siete meses. Los dos viajeros salen de Veracruz en abril de 1870 y llegan a Saint Nazare en Francia a principios de mayo. Se detienen en Paris y salen para España, Portugal, Italia, Austria, Budapest, 
Praga, Polonia, Rusia, Alemania, Suiza, Holanda y Bélgica. Pasan a Inglaterra. En París se detienen siete meses y el 4 de junio de 1872 embarcan en Brest y llegan a Nueva York el 21. Los cinco meses que estuvieron en Estados Unidos recorrieron varias ciudades.

El libro es un libro de viajes y un diario autobiográfico, en que se mezclan las observaciones objetivas con los sentimientos subjetivos. A pesar de que el viaje coincide con los momentos más turbulentos y decisivos de la historia de Europa, no hay referencia ninguna a la política. Isabel se demora en detalles del ambiente de lujo en que se movían. Ninguna observación sobre el mundo de los pobres, reflejo del abismo que separaba a las clases sociales.

En el verano de 1870, Antonio e Isabel pasan los meses de julio y agosto en la montaña palentina. Una estancia y un ambiente rural del todo diferente de los escenarios en los que se movía la pareja. Llegaron en tren desde Madrid a Aguilar de Campoo en la tarde del 2 de julio. Hicieron noche allí, debido al agotamiento de Isabel. El 3 de julio emprenden el camino hacia San Juan de Redondo, a donde llegan al día siguiente. La casa de los abuelos y tíos de Antonio y de su padre cuando niño les pareció triste. Los sentimientos cambiaron pronto ante el cariño con que les acogieron. Isabel encontró serenidad y reposo: «hemos estado contentos porque la familia de Barrio es muy amable y el aire del campo, los baños fríos y el reposo me han sido provechosos; pronto hará dos meses que llegamos a este sitio y el tiempo se ha pasado alegremente», escribió en sus memorias. Al despedirse el 27 de agosto todos lloraban. Durante su estancia en la montaña, el paisaje le aliviaba la melancolía, despertaba en ella sentimientos religiosos, incluso experiencias místicas. Captó muy bien la sociedad de los doce pueblos de la Pernía, igualitaria, con roles bien diferenciados. Admiró el trabajo de las mujeres y dedicó frases de cariño a las jóvenes dotadas de inteligencia y belleza. Dejó plasmadas las costumbres tradicionales de los pueblos, como normas habituales de buenas maneras, normas que se repetían en determinados tiempos y circunstancias, los convites entre amistades o entre determinados estamentos sociales. Isabel dejó una descripción etnográfica y sociológica de la comarca palentina de gran calidad literaria.

Agradecido quedó el matrimonio Mier y Pesado, pues, en 1904, cada una de las familias de San Juan de Redondo recibió la cantidad de 4.000 pesetas de entonces, como ayuda para comprar ganado y semillas. Don Antonio mandó restaurar la vieja iglesia y construir una escuela. El artículo se complementa con un Apéndice que reproduce las páginas de los Apuntes en las que Isabel narra la estancia del matrimonio en el pueblo. 


\section{TRABAJOS DEDICADOS A LA HISTORIA DE LA IGLESIA EN PALENCIA}

Manuel Revuelta fue ante todo historiador de la Iglesia. Su obra capital, que ocupó los años centrales de su labor de historiador, la constituyen los cuatro volúmenes dedicados a la historia de la Compañía de Jesús en España. En ellos se constata la maestría del autor en hacer memoria de la lectura e interpretación de la ingente documentación de archivo consultada. Muestra un estilo narrativo que va ganando con los años en sobriedad y tersura, acercándose al estilo coloquial, sin perder la precisión del discurso. Un estilo que refleja un diálogo del autor con los documentos, que le capacita a asumirlos en todas sus dimensiones. Historiador sacerdote jesuita que entra en coloquio con la sociedad plural y abierta. Recuerda en sus memorias: «redacté una historia minuciosa y total, que exigía conocer todo lo que se había escrito sobre la Compañía restaurada... además y sobre todo consultar todos los archivos disponibles de España y Roma» (Pérez García, 2019, p. 250).

Una conferencia de Manuel Revuelta tenida en verano de 1978 en Aguilar de Campoo sobre la desamortización, la publicó, en PITTM, de 1979 (Revuelta González, 1979). Busca seguir el proceso de desamortización y exclaustración en un municipio, un mundo en pequeño, que permite seguir en concreto todas las fases de desamortización de bienes eclesiásticos que llevan a la extinción de la vida religiosa en común. Aguilar contaba con el monasterio de Santa María la Real de religiosos premonstratenses, el convento de religiosas franciscanas de Santa Clara, la iglesia colegiata, beneficios eclesiásticos y cofradía.

El monasterio premonstratense de Aguilar era un colegio de filosofía para los jóvenes premonstratenses. La comunidad era querida y respetada en el pueblo. Había logrado sobrevivir, a pesar de la supresión durante el Trienio constitucional de 1820-23, pero en septiembre de 1835, el decreto de supresión de las órdenes monacales supuso el abandono definitivo del monasterio, dando fin a nueve siglos de vida monacal. La ley de regulares de 1837 suprimía también los conventos de religiosas. Se adueñaba de sus bienes, pero les permitía seguir habitando el convento con la prohibición de admitir novicias. Se mantienen con una pensión del Estado.

Con el decreto de 1836 se pusieron en venta los bienes de las comunidades religiosas. En el verano de 1837 se tuvo la primera subasta de bienes del monasterio de Santa María la Real situados en el término de Aguilar. La subasta de seis tierras de 19 hectáreas la adquirió un solo comprador. La segunda subasta, en mayo de 1839, ofrecía cinco fincas urbanas y 22 rústicas que sumaban 32 hectáreas de extensión, ofrecidas a subasta de una e una. 
Un solo pujador vecino de Reinosa adquirió el lote por más de medio millón de reales. El mismo postor adquirió por 100.000 reales un molino dentro del monasterio y dos vecinos de Potes lograron tres fincas por el precio de 132.000 reales.

Bajo la regencia del general Baldomero Espartero comenzaron a ser puestos en venta los bienes de la colegiata de San Miguel, de la iglesia de Santa Cecilia y de San Andrés. En octubre de 1843 salieron a subasta 187 tierras que sumaban 124 hectáreas cuatro casas del cabildo y terrenos de 9 hectáreas de Santa Cecilia y de las cofradías. Se subastaron en 6 lotes. Un solo licitador de Palencia adquirió el 80\% de lo subastado.

Las subastas de los bienes del convento de Santa Clara se tuvieron en noviembre de 1843 y en febrero de 1844, mientras las religiosas habitaban el convento. En noviembre de 1843 se subastan dos tierras, cuatro prados, dos huertos y tres casas. Se llevó el lote un solo comprador. En la subasta de febrero de 1848, un licitador adquirió un lote de 25,92 hectáreas de tierras de sembradura, otro compró tres pequeños prados. Por estas mismas fechas se fueron comprando las posesiones que las clarisas tenían fuera de Aguilar. En la década de 1844-54, los políticos moderados que gobiernan suspenden la venta de los bienes del clero secular y de las religiosas y exigen que se devuelvan a los obispos los bienes no vendidos de los conventos de religiosos extinguidos. La revolución de 1854 volvió a la política de desamortización, a pesar del concordato firmado con la Santa Sede en el año 1851. La reacción moderada de 1856 dejó en suspenso la venta de bienes del clero, mientras buscaba un arreglo con la Santa Sede, que consistió en títulos de deuda a la Iglesia a cambio de las fincas incautadas, mediante un acuerdo del 4 de abril de 1860 entre el Gobierno de España y el Papa Pío IX.

Conseguido el arreglo de la desamortización pactada, se liquida en 12 subastas lo que quedaba de bienes eclesiásticos en Aguilar. En 1865-66 se subastaron bienes por valor de 147.451 reales. Diez vecinos de Aguilar fueron los compradores de seis casas y varios lotes de tierras y prados, si bien uno solo se llevó el 60\% de las fincas rústicas. La revolución de 1868 vuelve a la carga con la incautación de los conventos que aún existían. En esta ocasión las carmelitas de Aguilar de Campoo fueron trasladadas al convento de Astudillo el 10 de octubre de 1870. En 1871 sale a subasta la huerta del convento de Santa Clara adquirida por un vecino de Aguilar en 2.570 pesetas. La casaconvento con la iglesia y sus aledaños salió a subasta tres veces entre 1871 y 1872, pero no se presentaron licitadores.

En las conclusiones Manuel Revuelta pone de relieve la incuestionable realidad de las tierras de la Iglesia puestas en venta: un solo comprador adquirió las 103 hectáreas de las fincas del monasterio, otro se hizo con las 
fincas de la colegiata y otro con las de Santa Clara, adquiridas a muy alto precio. De las tierras sacadas a subasta, solo un comprador adquiere el $48 \%$ y otro el 36\% entre 25 compradores. De los compradores 11 son de Aguilar y nueve de fuera. De los cinco restantes no consta su procedencia. Los nueve forasteros pagan el $77 \%$ de los precios. Juicio final del autor: «También en Aguilar era necesario hacer desamortización, dada la gran extensión de fincas de manos muertas, pero se hizo de tal modo que ni económica ni culturalmente favoreció al verdadero pueblo» (Revuelta González, 1979, p. 201).

En el año 1985, Manuel Revuelta fue invitado a participar en el primer Congreso de Historia de Palencia celebrado en Monzón de Campos del 3 al 5 de diciembre de 1985. Presentó una ponencia (Revuelta González, 1987) en la que estudia la labor del obispo de la diócesis de Palencia don Juan Lozano Torreira a través de dos informes que el obispo dirigió al Papa, uno de 1870 a Pío IX y otro en 1882 a León XIII.

El santiagués Juan Lozano Torreira (1814-1891), licenciado en Derecho y doctor en Teología, canónigo lectoral de Sagrada Escritura en la catedral de Astorga, profesor en las Universidades de Santiago de Compostela y Oviedo y Rector de los Seminarios de ambas ciudades, era especialmente estimado por el cardenal arzobispo de Santiago don Miguel García Cuesta, quien tuvo que convencerle para que aceptase su nominación como obispo de Palencia el 8 de enero de 1866.

Él es un testigo cualificado que nos habla con precisión sobre el estado de la diócesis a finales de siglo en dos momentos altamente significativos. Revuelta ha leído estos documentos haciendo una autentica hermenéutica, teniendo en cuenta los tiempos en que fueron escritos y el acento que el obispo, hombre de libros de Iglesia, predicador y profesor, devoto pragmático, en plena madurez con experiencia de gobierno y alto grado de cultura, pone en las cosas esenciales. Pertenecía a la generación del Concordato de 1851, que puso fin a la época de Mendizábal. Era, como todo el episcopado de su tiempo, fiel devoto del Papa Pío IX y entregado a los principios del Syllabus. Al poco de llegar a su diócesis acude en 1867 a Roma para celebrar el centenario del martirio de San Pedro y expresar su solidaridad al Papa. Era, por supuesto, cordial antiliberal a conciencia.

Año y medio llevaba en la diócesis, cuando estalló la Revolución de septiembre de 1868. En el informe de 1870, el obispo concreta los efectos producidos en la diócesis en cuatro hechos: 1 . El 12 de octubre de 1868 era suprimida por decreto la Compañía de Jesús. En la provincia de Palencia la consecuencia fue el cierre del colegio de segunda enseñanza, en el que, desde 1854, los jesuitas venían educando en régimen de internado a más de trescientos alumnos procedentes de todas las regiones. Estaba situado en 
el antiguo monasterio cluniacense de San Zoilo en Carrión de los Condes. 2. El 17 de octubre, el ministro de Gracia y Justicia, Antonio Romero Ortiz ordenaba por decreto la reducción a la mitad de los conventos de religiosas. A pesar de las gestiones ante el Gobernador, no se pudo evitar el cierre de cuatro conventos en Palencia. 3. El decreto del 22 de octubre de 1868 suprimía la dotación estatal que el artículo 35 del Concordato asignaba a los seminarios. El obispo estaba entonces terminando de reconstruir el seminario. Aunque tuvo que interrumpir las obras, el seminario permaneció abierto. 4. La supresión de las conferencias de San Vicente de Paúl por el decreto de 29 de octubre, muy florecientes en la provincia de Palencia, en la que actuaban las dos ramas de caballeros y señoras. A ello se añadió la reducción de los presupuestos para el culto y clero, que el gobierno cumplía tarde y mal.

El obispo alaba al clero palentino que, en medio de la pobreza y de las suspicacias, mantenía su pureza de doctrina y la obediencia al prelado. De las religiosas, el obispo resaltaba que, si bien el gobierno alentaba su secularización, ni una sola había sido infiel.

En cuanto al comportamiento religioso de los diocesanos, el obispo constata una saludable reacción religiosa, que impulsaba a la confesión y a la defensa de la fe. Resalta la existencia de las nuevas asociaciones de seglares dedicados e una vida más exigente, a la atención al prójimo y a la propaganda. En el segundo informe el obispo refleja el cambio político con la derogación de la legislación anticlerical del sexenio y se extiende en los signos de una renovación católica interior impulsada por los mismos fieles. Habían vuelto los jesuitas a Carrión y los Pasionistas se instalaron en Peñafiel. Cuatro congregaciones de religiosas se dedicaban a la enseñanza o a la atención a los ancianos y enfermos, además de las religiosas de clausura ya existentes. El obispo visitó todos los pueblos de la diócesis. El clero regular desplegó una campaña de evangelización con las misiones populares. El 4 de junio de 1891 moría el obispo Lozano. Dejaba una diócesis en donde la fe estaba sólidamente arraigada. Una fe tradicional abierta a actitudes y acciones religiosas más acomodadas a las urgencias del tiempo.

«Entre los temas de Historia Contemporánea de Palencia no podía faltar la Historia de la Iglesia. A pesar de la secularización creciente de la época contemporánea, las creencias religiosas, vividas en el seno de las conciencias o manifestadas en instituciones eclesiales, están ahí como una realidad histórica que no se debe ignorar... La fe religiosa, a parte de sus dimensiones espirituales y teológicas, tiene repercusiones muy concretas en el pensamiento, vida y acción de los individuos y de los pueblos. En un pueblo como el palentino, de hondas raíces tradicionales, el influjo del factor religioso es muy importante» (Revuelta González, 1988). 
Con este claro presupuesto presenta Manuel Revuelta su ponencia en el II Congreso de Historia de Palencia. En ella trata del obispo don Enrique Almaraz, quien desde 1893 a 1907 dirigió la diócesis palentina y logró hacer crecer la renovación religiosa que había iniciado su antecesor don Juan Lozano.

Le tocó a don Enrique Almaraz dirigir la diócesis en el gozne de los dos siglos, en un periodo crucial de la Iglesia, entre la Rerum Novarum de León XIII, que ofrece al mundo un programa de justicia y paz social y la Pascendi junto con el decreto Lamentabili de Pío X, que da un portazo al modernismo, atrincherándose en la defensa cerrada de principios doctrinales con exigencias de exclusividad.

La restauración religiosa que había empezado a despuntar en España en el reinado de Isabel II tomó fuerza durante el sexenio revolucionario y logró madurez y fortaleza en los años de paz de la Restauración alfonsina. Es la época de la gran actividad de las Órdenes y Congregaciones religiosas, de las grandes manifestaciones de fe en los actos de culto multitudinarios, de las peregrinaciones, de los congresos católicos, de la plétora de creación de medios de comunicación, centros de enseñanza y de asistencia social.

Pero es también la época del desastre colonial del 1898, del desgaste político, de la depresión económica y, en lo que toca a la Iglesia, del recrudecimiento anticlerical, con el que intelectuales y pedagogos librepensadores intentan poner trabas a la enseñanza católica. Sobre todo, a principios del siglo XX, los liberales concentran su política anticlerical contra las congragaciones religiosas. La recién creada UGT ataca a los círculos católicos de obreros y los acusa de servir a las clases dominantes.

Cuando el salmantino Enrique Almaraz tomó posesión de la diócesis de Palencia, el 22 de abril de 1893, contaba 44 años. Era un hombre de brillantes cualidades. Doctor en Teología, tenía experiencia docente, pastoral y de gobierno. Las ideas de Almaraz brotaban de una teología tradicional. Hombre de profunda fe, se debate entre la angustia y la esperanza. Estaba convencido de que había que lograr la regeneración cristiana de la sociedad mediante la prensa, las asociaciones y toda clase de obras benéficas y sociales. Estimulaba a los sacerdotes a entregarse a la acción social y a los cristianos a participar en la vida pública.

La ciudad era una ciudad levítica, donde se dejaba sentir la presencia del clero. La catedral contaba con un cabildo muy bien formado. El seminario era el centro cultural más importante de la ciudad. No se hacían notar en Palencia actitudes anticlericales. No se dieron en ella divisiones entre católicos.

En la acción pastoral, Almaraz fomentó las misiones populares, que ya habían dado fruto en el pontificado de su antecesor. Los encargados de organizarlas fueron, sobre todo, jesuitas, pasionistas, dominicos y claretianos. 
En el pontificado de Almaraz se dieron 300 misiones populares, 43 solo en el año 1900. Otro incentivo de la vida cristiana se dio con las peregrinaciones. Él mismo peregrinó a Roma en tres ocasiones. Dentro de la diócesis se organizaron las peregrinaciones eucarísticas a las ermitas o santuarios de la provincia o peregrinaciones con ocasión de jubileos, como las que organizaron los arciprestazgos de la diócesis a principio de siglo en homenaje a Cristo Redentor. Estas peregrinaciones de la diócesis despertaron en el pueblo la conciencia del valor artístico de los monumentos arquitectónicos vistos por ellos como herencia de fe y cultura. Durante el pontificado de Alcaraz se construyeron nueve templos parroquiales y se restauraron setenta, entre ellos la cripta de San Antolín y el ábside de la catedral, San Martín de Frómista, San Andrés de Arroyo y San Juan de Baños. La Iglesia participó activamente y el obispo, gran animador de tales iniciativas, supo ganarse el apoyo de las autoridades.

Preocupación especial tuvo por la formación del clero. Para ello promovió los Ejercicios Espirituales anuales, retiros mensuales y conferencias. Fundó el Montepío Diocesano y la Obra para el fomento de vocaciones sacerdotales.

Alcaraz se encontró al llegar a Palencia con una entidad fundada en 1869 por el sacerdote José Madrid y Manso: la «Propaganda Católica». Comenzó como una escuela de adultos. Poco después editaba una revista con el mismo nombre. Enseguida nació la sección «La juventud católica». Se creó una biblioteca. En 1884 nacieron la Caja de Ahorros, el Círculo de Obreros y la Escuela de obreros se transforma en «Escuela de Artes y Oficios». La «Sociedad de Socorros Mutuos» se funda al año siguiente. Al poco de llegar, Almaraz convirtió Propaganda Católica en obra diocesana e instaló la Escuela de Artes y Oficios en el palacio episcopal. Uno de los aspectos más destacables fue el carácter mixto de sus miembros y actividades. En la revista Propaganda Católica se exponían los principios básicos de la doctrina social de la Iglesia como única solución entre dos extremos que juzgaban condenables: el individualismo liberal y el igualitarismo socialista. Demasiado tajantes eran en el rechazo de los adversarios y simples e idealistas en sus soluciones. Con la gran crisis del primer decenio del siglo XX la revista evolucionó hacia soluciones más concretas, a las que el obispo estuvo siempre muy atento.

El Papa Pío X nombra a Enrique Almaraz arzobispo de Sevilla el 18 de abril de 1907. El 27 septiembre de 1911 lo erige Cardenal. En septiembre de 1914 asistió al cónclave que eligió a Giacomo dalla Chiesa papa Benedicto XV. El 15 de noviembre de 1920 era nombrado arzobispo de Toledo y Primado de España. Murió en Toledo el 22 de enero de 1922, el mismo día en el que Benedicto XV expiraba en el Vaticano. 
En el III congreso de Historia de Palencia, Manuel Revuelta continuó con la labor de los dos anteriores (Revuelta González, 1995). Comienza con un juicio sobre el estado religioso del pueblo palentino tal como se refleja en los informes y cartas pastorales de dos de los obispos que rigieron la diócesis en este tiempo: Ramón Barberá (1914-1924) y Agustín Parrado (1925-1934). El primero enviaba, en octubre de 1917, el preceptivo informe a la Santa Sede. Al calibrar el estado religioso de «esta grey», juzga que no es excelente, pero puede considerarse de laudable y satisfactoria. Casi todos se dedican a tareas agrícolas y su vida es morigerada, aunque se dan en ellos la profanación de los días festivos y la blasfemia. Los hombres se confiesan por Pascua, los jóvenes, tanto ellos como ellas, con más frecuencia. De las mujeres, un número consistente acuden a los sacramentos con frecuencia, las demás solo comulgan una o dos veces por año. No se celebran matrimonios civiles. Poquísimos mueren rechazando los sacramentos.

La religiosidad de los palentinos llegó a convertirse en un tópico. Pero había defectos. La rutina era señal de una anemia que debilitaba la salud de la vida cristiana. Esto lo fue viendo el obispo y dio aviso de ello en sus pastorales. La pastoral que escribe en marzo de 1919 todavía juzga a la diócesis como reducto de fe, pero advierte que se debilita el sentido religioso en ciertos sectores, en los que va penetrando la concepción materialista de la vida. En la pastoral de noviembre del mismo año denuncia en la diócesis las secuelas de la crisis que en España causó la guerra mundial de 1914-18: el afán inmoderado de riqueza con menoscabo de la justicia y la paz, seguido del desorden moral social.

En los «felices años veinte» ocupan la escena social y política palentina una serie de familias unidas entre sí por vínculos de parentesco y económico-empresariales, junto con personas de profesiones liberales. Es la nueva burguesía. En ella hay católicos practicantes que provienen de familias acomodadas de origen rural. Otro grupo lo forman los que se han enriquecido o se siguen enriqueciendo en la especulación agropecuaria y crediticia. Están también los propietarios de negocios comerciales e industriales de mentalidad liberal, los asiduos al Casino. Está la intelectualidad, en mayoría aséptica en lo religioso, los frecuentadores del Ateneo. Todos han contribuido al progreso material que ha cambiado la fisonomía de la ciudad y ha llevado a una existencia más desahogada, que vive más en la calle, que adopta un estilo de vida más laxo y desenvuelto y frecuenta poco el templo.

El obispo Barberá publicó en 1920 la pastoral Sobre la modestia cristiana. Cruzada urgentísima, en la que entraba en detalles de cómo debía vestir la mujer. Pero fue su sucesor Agustín Parrado quien se mostró obsesionado por las malas costumbres. Prohibió la entrada en las iglesias a las mujeres que, 
según él, no iban vestidas con modestia, y describía detalladamente cómo debían ir vestidas. Condena el cambio creciente en diversiones, en publicaciones, en el vestir femenino, en gimnasios, deportes, baños... En 1930 creaba la Legión Católica contra la inmoralidad pública.

Mucho más grave era el alejamiento de la Iglesia de algunos sectores burgueses y obreros. Más que un alejamiento hostil o abiertamente anticlerical, era alejamiento por indiferencia. Tal vez el rigorismo doctrinal unido a un paternalismo clerical influyó en la retirada de la clase trabajadora de las obras sociales de la Iglesia, hasta entonces muy demandadas, como la Escuela de Artes y Oficios.

El clero fue el promotor principal de la propaganda católica en esta época, en la que el apostolado seglar se concebía como una extensión del activado por los sacerdotes.

El primer tercio del siglo XX tuvo cuatro obispos de gran personalidad. Don Enrique Almaraz fue el gran animador de la vida católica en Palencia. Creó la base de las iniciativas posteriores. Le sucedió don Valentín García Barrios (1907-1914), que era un anciano pontevedrés enfermo. Intentó seguir las directrices de Pío X contra el modernismo, creando un ambiente de sospecha que no propiciaba novedades. Renunció al obispado.

Las dos grandes cualidades de don Ramón Barberá fueron su espíritu religioso y su sentido social. Muy atento a los problemas del mundo y de España y muy cercano a la gente de Palencia. No se cumplieron sus grandes planes, lo que explica el pesimismo de sus últimos años. Tras un año de sede vacante, llega a la diócesis don Agustín Parrado (1923-1934), nacido en Fuensaldaña (Valladolid), llega a la diócesis de Palencia a sus 46 años. Estuvo identificado con los ideales de Pío XI, el Papa de la Acción Católica. Su temperamento idealista le llevaba a un rigorismo frente a ideas y conductas que chocan con la doctrina moral católica, lo que le inclinaba a la intolerancia. Intentó coordinar todos los grupos católicos de la diócesis en un solo organismo: la Acción Católica Diocesana. Impulsor de grandes símbolos como expresión de la fe colectiva, erigió el monumento El Cristo de Otero, expresión de la devoción al Corazón de Jesús, Cristo Rey erigido en el lugar adecuado y plasmado por un artista genial, Victorio Macho.

La diócesis estaba servida por un clero abundante compenetrado con el pueblo y en general, morigerado, piadoso y bien instruido. Los curas de las parroquias rurales vivían con lo justo, que era muy estrecho. Pero, ni siquiera los canónigos sacaban para vivir con la decencia que exigía su condición social. El clero regular creció en este tercio de siglo. En 1931, los religiosos tenían en la diócesis 16 casas, cinco de ellas en la ciudad, dedicadas a la enseñanza, la beneficencia y la asistencia religiosa, destacándose algunas en 
las misiones populares. En la diócesis había 16 monasterios de religiosas de clausura, siete en la ciudad y 28 conventos; 11 en la ciudad, de religiosas de vida activa dedicadas a la educación fundamentalmente, a la enseñanza y a la beneficencia.

La abundancia de clero y de religiosos no levantaba oposición en Palencia, y eso que la época era pródiga en ataques anticlericales. En los centros culturales como la Sociedad Económica de amigos del País, el Ateneo o el Casino, donde se reunía la burguesía de cultura laica, nunca se pronunciaron conferencias abiertamente anticlericales.

La política laicista de los liberales, dominante en este período, contó en Palencia con una reacción católica defensiva resuelta y valiente. Se convocaron grandes mítines y grandes campañas de prensa. Se destacó la Propaganda Católica.

Desde el asesinato de Canalejas en 1912, hasta la proclamación de la Dictadura en septiembre de 1923, se pasa en la Iglesia, de una protesta sistemática contra el laicismo a una acción organizada en el campo social alejada de la política. En Palencia fue el momento de los sindicatos agrarios.

Cierra Manuel Revuelta su larga y algo reiterativa ponencia exponiendo la influencia social y religiosa de las asociaciones católicas seglares. Se demora sobre todo en la Acción Católica y, dentro de las diferentes asociaciones, en la sindicación agraria. El obispo Parrado reorganizó todas las asociaciones católicas masculinas y femeninas de la diócesis unidas en acción común, manteniendo cada una su propia independencia. Puso especial interés en la organización de las Juventudes Católicas. Al fin de noviembre de 1930 se tuvo la primera asamblea de la Acción Católica de Palencia, muy bien organizada, con poca asistencia de seglares. ¿Tal vez era una callada observación de que querían trabajar con el clero, pero no tutelados por él? Estas asociaciones eran de hecho una poderosa fuerza social comprometida en la vida cristiana responsable.

Los sindicatos agrarios eran los más pujantes. El triunfo del sindicalismo agrario se debió a la amenaza de las fuerzas revolucionarias, que se veían como disolventes de los valores tradicionales y del orden social, y al desencanto con la política caciquil tanto de conservadores como de liberales. La Propaganda Católica y el grupo de sacerdotes unidos a ella promovieron los Círculos Obreros, en los que nacerían los sindicatos agrarios. Desde 1912, el jesuita nacido en Carrión de los Condes, Sisinio Nevares, junto con el gran propietario agrícola Antonio Monedero, fueron los propagandistas decisivos en la creación de sindicatos agrarios. En Palencia fue el obispo Barberá uno de los decididos defensores. Los sindicatos agrarios se declaraban ajenos a 
la política, aunque la masa de campesinos, adherida a posiciones conservadoras, sirvió de alternativa al liberalismo y socialismo.

Manuel Revuelta era recibido en la Institución Tello Téllez de Meneses de Palencia el día 4 de mayo de 1992. Elige como materia de su comunicación: «Origen, ocaso y renovación de los conventos palentinos» (Revuelta González, 1994). Se trata de un trabajo escrupulosamente elaborado y refrendado por las notas a pie de página, que ocupan un tercio del texto.

En un densísimo resumen de diez páginas recuenta todos los monasterios, conventos y casas de religiosos de la ciudad y provincia. Al final del recuento nos testimonia: "Por debajo de los hechos memorables y de los nombres ilustres, los conventos han recogido las palpitaciones del pueblo sencillo. Cada convento aglutina un pequeño mundo de colonos y clientes, de enfermos y peregrinos, de colegiales y devotos. Todos fueron focos de espiritualidad. Muchos eran centros de estudio y de cultura. Algunos alentaron devociones populares enraizadas en el alma del pueblo. A pesar de los muchos documentos y obras de arte desaparecidas, los conventos nos han legado preciosos testimonios para el conocimiento de nuestra historia provincial y local. No solo de la historia religiosa, que constituye el alma de aquellas instituciones, sino de la economía, la explotación agraria, el derecho y la cultura» (Revuelta González, 1994).

En el cuerpo del discurso expone cronológicamente el proceso de supresión de los conventos en la provincia de Palencia. a) El primer ensayo se da durante la Guerra de la Independencia, llevado a cabo por el rey José, ocupada como estuvo la provincia por los franceses entre 1808 y 1813. b) El segundo ensayo durante el trienio constitucional de 1820 a 1823 . c) La supresión definitiva de 1835 a 1836 . En un relato concentrado, pero fluido y vivo, Revuelta nos pone ante cada uno de los lugares y en cada uno de los tiempos, como si fuese un testigo que nos narra, todavía conmocionado, lo que ha visto, oído y sentido ante tales hechos. Acciones condenables no solo imputables a los políticos liberales, cuyo fin último era domeñar a la Iglesia sometiéndola al poder civil. Condena merece una burguesía palentina que, buscando inmediatas ventajas materiales, no tuvo escrúpulos en comprar los bienes desamortizados.

La renovación de las comunidades de religiosas en Palencia se da, sobre todo, a partir de 1877 . Vuelven los que habían tenido que dejar sus casas y, en el caso de las religiosas, sobre todo, se abren nuevas fundaciones, en especial de congregaciones misioneras

A pesar de las variedades de lugar, tiempo y fortuna de nuestros conventos, una línea les da unidad y sentido: la fe religiosa en servicio del pueblo. 
Con ocasión del bicentenario de la Guerra de la Independencia, Manuel Revuelta ofrece un modesto, pero jugoso artículo sobre los aspectos religiosos en esa guerra (Revuelta González, 2008).

En la Guerra de la Independencia se dan manifestaciones de sentimientos religiosos de forma espontánea entre el pueblo. No faltaron en Palencia, sobre todo en los momentos más críticos de los primeros meses de la guerra, de junio a noviembre de 1808 .

La primera llegada de la francesada a Palencia aconteció el 12 de enero de 1808. Llegan 3000 soldados al mando del mariscal Jean Baptiste de Bessières, creando una situación insostenible, con exigencias de alojamiento y manutención. El convento de San Francisco quedó ocupado como cuartel general y el de San Pablo también ocupado por las tropas.

Hubo un levantamiento de la ciudad. El 1 de junio se formó la Junta de Armamento y Defensa. El obispo Javier Almonacid animó a todos a acudir en defensa de la religión y de la patria. El 4 de junio llevaron en procesión la imagen de la Virgen de la Calle a la catedral y comenzaron un novenario, que no se terminó, porque el 7 entraban las tropas francesas en Palencia comandadas por el general Antoine Louis de Lassalle que, al paso por Torquemada el día anterior, aplastó la resistencia, saqueó la villa, la incendió incluida la Iglesia después de arramblar con todas las alhajas y vasos sagrados. Palencia se libró del saqueo gracias a la intercesión del obispo y del concejo municipal.

La participación del clero en la instigación a la insurrección y a la resistencia es evidente, lo que acentúa el carácter religioso de la guerra. No todo el clero colaboró; hay que distinguir entre zonas ocupadas y libres, clérigos afrancesados y clero resistente.

En Palencia, la ocupación francesa pasó por períodos intermitentes en dependencia de los ataques y contrataques de los ejércitos en lucha. El 7 de junio de 1813 llega el general Francisco Javier Castaños a Palencia, que queda definitivamente bajo el dominio español.

En el conjunto de España, los eclesiásticos comprometidos con la insurrección forman dos grupos: $1 .^{\circ}$ los insurrectos armados, compuestos por curas y frailes guerrilleros, por soldados regulares o cruzados, y $2 .^{\circ}$ combatientes en las filas de los ejércitos.

En el clero hubo división acerca de la licitud de tal comportamiento. Los afrancesados condenaban la colaboración bélica de los ministros de Dios. Los patriotas lo admitían. Todos sabían que las leyes de la Iglesia prohibían al clero empuñar las armas. Pero los motivos que esgrimían no venían de la teología, sino de la ofuscación de la razón. 
La provincia de Palencia pululaba de partidas de guerrilleros. Se hicieron famosos el militar Juan Díaz Porlier, apodado el Marquesillo y el militar natural de Revenga Bartolomé Amor. Curas líderes de partidas de guerrilleros fueron Jerónimo Merino Cob, al que se le llamó el cura Merino y Juan Tapia, natural de Astudillo, que se movió por el Cerrato.

Una forma de colaborar el clero en la rebelión y resistencia fue su participación en las primeras juntas provinciales locales. Una cuarta parte del promedio total de los componentes de las juntas fueron eclesiásticos. Incluso obispos llegaron a presidir las juntas. Fueron notorios don Pedro Quevedo y Quintano, obispo de Orense y Rafael Menéndez de Luarca, obispo de Santander.

En Palencia formaron parte de la primera junta de armamento dos canónigos. El obispo mismo fue presidente provisional. Pero no se dio en Palencia la exaltación extrema de otras partes. La presencia de los clérigos en las juntas se debía, más bien, a que éstos formaban parte de la prelacía social en las provincias. En las zonas libres predomina, por parte del clero, la motivación religiosa del conflicto, que las autoridades apoyan. Los sermones más virulentos justificando religiosamente la guerra se pronunciaron en esta zona.

Una forma de ayuda a la guerra fue la ayuda económica de la Iglesia a la causa. Hay que tener en cuenta que esta colaboración doctrinal, moral y económica por parte del clero actuaba en la España afrancesada al servicio del rey José.

Hay, con todo, que contrastar este colaboracionismo por parte de muchos sacerdotes con la misión de apaciguamiento que se dio seguramente con más frecuencia. En las regiones dominadas por los españoles actuaron los curas para evitar represalias contra los franceses y sus seguidores. Se conocen muchos casos en los que el sacerdote intervino para calmar a la gente. Tenemos el caso de Palencia, en donde el obispo, el 7 de junio de 1808, actuó de mediador ante el general Lassalle y así evitó el saqueo de la ciudad y más tarde, el 11 de noviembre actúa de pacificador ante el general Eduard Milhaud.

Otra forma de propaganda de la insurrección fue el uso de motivos tópicos religiosos populares. Una propaganda maniquea hacía de Napoleón la figura del malvado impío y de los franceses los introductores del ateísmo y de la inmoralidad en España, en contraste con la fe del pueblo español. Caricaturas, panfletos, hojas volantes, coplas, representaciones teatrales llevaban siempre el matiz religioso. Un género literario popular fueron los catecismos patrióticos.

La motivación religiosa formó parte sustancial del espíritu del pueblo con todas sus limitaciones y deformaciones. Fue vivida como un ataque a la dignidad de la persona. La religión católica era un elemento aglutinante imprescindible. Esto explica la acusada presencia del clero y de la Iglesia. 
Pero la religión fue manipulada con fines políticos. Seis mandatos de la Junta Central implican al clero y a la religión en la defensa de la patria. En el decreto de diciembre de 1808 se afirma. "La guerra en que nos hallamos es santa y de religión»; en la circular del 12 de febrero de 1809 se pide expresamente la colaboración de los eclesiásticos, incluso usando las armas. Esto convertía la guerra en cruzada o guerra santa. Los abusos contra personas y símbolos religiosos cometidos por los ejércitos franceses y las desviaciones doctrinales de la política religiosa del gobierno afrancesado que se juzgaban opuestas a la ortodoxia de la fe católica, les servían de argumento.

Es cierto que los atentados de los ejércitos franceses contra las personas, edificios bienes y símbolos de la Iglesia fueron muchos y graves, pero hay que situarlos en el contexto de la guerra.

Rapiñas, asesinatos y abusos los cometieron también los aliados ingleses del general John Moore al retirarse de Galicia en diciembre de 1808. Las tropas de Wellington hicieron lo mismo entre 1812 y 1813 en Ciudad Rodrigo y Badajoz, camino de Salamanca, y sobre todo, después de la batalla de Vitoria en San Sebastián. En todos los casos no se libraron las iglesias de la profanación y destrucción. Las mismas tropas españolas hicieron lo mismo, no digamos las patrullas de los guerrilleros. La guerra de liberación fue una guerra inhumana. Los españoles estuvieron en dos bandos, divididos en afrancesados y nacionalistas. Ambos se confesaban católicos. En el clero se dio la misma división la gran mayoría en el clero bajo, muchos en el clero medio y en obispos pocos clamaron por la guerra santa. Afrancesados lo fueron de circunstancias en actitud pasiva, siguiendo la ley del mal menor. Pocos lo fueron convencidos. Donde más afrancesados convencidos se dieron fue en el clero catedralicio.

\section{HISTORIA Y ESPÍRITU EN TIERRAS PALENTINAS}

Un género que Manuel Revuelta inició en su última época fue reunir en un volumen artículos inéditos con otros ya publicados que tratan contenidos relacionados. El tercero de este género es Historia y espíritu en tierras palentinas: Camino de Santiago y otros afanes (Revuelta González, 2010). Se lo publicó, en el año 2010, la Institución Tello Téllez de Meneses en homenaje a los veinte años de haber sido admitido como académico de número, coincidiendo con que ese año era año santo compostelano. Un libro sobre Palencia, que se encabeza con esta dedicatoria que ya insinúa mucho: «A la 
memoria de mis padres, Fortunato y Gregoria, que me enseñaron a amar y a conservar la fe».

Nos ofrece Manuel Revuelta este libro concebido en la cima de su vida, en el que quiere exteriorizar lo mejor de sí mismo: un historiador que se vive como sacerdote jesuita al servicio de la Iglesia y que contempla el mundo entero desde el mundo familiar suyo con «una perspectiva espiritual, desde el aliento de la fe, que dio sentido a nuestro pasado y ayuda a comprenderlo desde el nuestro presente» (Revuelta González, 2010, p. 11).

Digno de resaltar es que Manuel Revuelta escoge un artículo que había publicado en el anuario Otero (Revuelta González, 2007), para presentarnos, en la primera parte del libro, el primer pueblo que se encuentra en el Camino de Santiago al entrar en la provincia de Palencia: «Boadilla y su Camino», la apretada biografía de uno de los seis primeros compañeros de San Ignacio en París, nacido en ese pueblo, y que será uno de los diez «amigos en el Señor» que, en 1540 fundan la Compañía de Jesús: el P. Nicolás de Bobadilla.

Bobadilla fue un andariego incansable por los caminos de una Europa dividida por la reforma protestante. Comenzó trabajando en el sur de Italia cuatro años, de 1537 a 1541, enviado por Paulo III a reformar la diócesis de Bisignano y de Viterbo. Los seis años de actividad de Bobadilla en Alemania (1542-1548) supusieron la forja definitiva de su personalidad. El Papa lo envía a la dieta de Espira como consejero del legado pontificio Jerónimo Morone. Terminada la dieta de Espira, el rey Fernando de Austria lo lleva consigo a Innsbruck y de allí a Viena, donde Bobadilla toma contacto con los escritos de Lutero y Melanchton. En la dieta de Nuremberg de 1543 tuvo ocasión de deliberar con importantes figuras de los protestantes. Está en la dieta de Worms en 1545. En la 1546 de Ratisbona es recibido con especial interés por la Corte del Emperador. La dieta se cerró con la creación de la Liga de Esmalcalda por los príncipes protestantes, que desembocó en la guerra. Nombran a Bobadilla capellán de las huestes pontificias. En los combates del verano de 1546 es herido cerca de Ingolstadt. En agosto de 1547 llegaba a la dieta de Augsburgo. La decisión del Emperador era lograr la paz en Alemania a toda costa. Presentó la fórmula de concordia que fue refrendada el 24 de mayo de 1548. Bobadilla había hecho circular una crítica adversa a la fórmula de concordia. Por orden del Emperador fue expulsado de Alemania y conducido en secreto a Trento. Se cerraba así su ingente labor, de manera humillante para él, que había sido interlocutor obligado y protagonista en todos los foros donde se decidía el destino de Europa y de la Iglesia.

Llegado a Roma lo reciben el Papa Paulo III y varios cardenales, a los que informa sobre el estado de cosas en Alemania. En mayo de 1549 está en Nápoles dedicado a la tarea de predicar, enseñar y atender a las necesidades 
espirituales de la gente. Vuelve enfermo a Roma en la primavera de 1551 . Nada más reponerse, el Papa lo envía a Brescia como visitador de la diócesis. De allí marcha a Ancona, donde la herejía invade las poblaciones. El Papa Julio III lo envía en 1554 a reformar una abadía benedictina. De vuelta a Roma, el Papa Paulo IV recién elegido, lo envía a Fabriano a otra reforma.

La más difícil de sus misiones fue, en 1558, la misión de la Valtelina, un valle alpino, paso estratégico de Austria y Alemania a Italia. La región estaba controlada por los suizos grisones protestantes. Muy duro fue para Bobadilla el año que trabajó allí: la población católica vive en extrema pobreza, gran parte no come pan, sino solo castañas, los lechos y las casas son como chozas de pastores y él se encuentra enfermo, casi desnudo y sin medios, pero con alegría y consolación espiritual.

El 20 de julio de 1559 el Papa Pío IV le encomienda la misión en la región costera de la actual Croacia, en los obispados de Zadar, Pola y Dubrownik, poblaciones amenazadas por los turcos. En junio de 1561 se encontraba de vuelta a Italia en Ancona, aquejado de fiebres cuartanas y sintiéndose a sus 52 años un anciano.

Pero le quedan todavía treinta años de vida y de trabajos. El sur de Italia será, a partir de ahora, su campo prevalente de actividad. Las ideas heréticas se filtran en las poblaciones de Calabria desde círculos nacidos alrededor de alguna figura eminente, como el círculo de Juan Valdés en Nápoles. Casi veinte años de trabajo gastó Bobadilla en formar y ayudar al clero, reconciliar a los que vuelven a la Iglesia, confesar y predicar. Tiene tiempo aún de fundar, visitar e inspeccionar colegios. Cuando en el verano de 1579 cumple 70 años, se dispone a retirarse a su querida Loreto, pero a comienzo de 1583 vuelve al sur de Italia. Tiene tiempo de recorrer, entre 1584 y 1585 las principales ciudades del norte de Italia. En mayo de este año zarpa de Génova a Roma. A punto estuvo su nave de ser abordada por los turcos. En Roma visita al nuevo Papa Pío V y vuelve a Loreto. Aún bajará a Calabria y Sicilia. En el verano de 1590 sale para Roma, donde ya enfermo pide que lo lleven a Loreto. allí muere el 27 de septiembre de ese año.

Nicolás de Bobadilla resalta por su fuerte vitalidad entre los primeros jesuitas. Una vitalidad puesta al servicio de la Iglesia. Sus mejores cualidades fueron generosidad sin condiciones, que una libertad diáfana jamás permitió que derivara en vasallaje. En el fondo es un alma humilde, que atrae a las personas de toda condición un espíritu observador, una mente lúcida, un ser sensible a los vínculos de la amistad, sobre todo con quienes compartía el mismo ideal de vida y entrega a Dios al servicio de su Iglesia.

Al segundo pueblo del Camino lo presenta el autor como «Frómista la milagrosa». Reparte la presentación en dos capítulos del libro, el capítulo 
segundo: «Ráfagas de historia y cuatro palabras» (pp. 33-41) y el capítulo tercero: «Un milagro para una villa» (pp. 43-63). Las «ráfagas de historia», que había publicado en la revista Peregrino, de la Federación de amigos del Camino de Santiago el año 1991, es un concentrado en dos páginas del artículo publicado en PITTM de 1987. Las «cuatro palabras» reproducen el pregón de las fiestas de San Telmo patrón de la villa, que pronunció el 5 de abril de 1991. Y ya se sabe que el género literario en tales circunstancias: exaltar en pocas palabras lo mucho bueno que el auditorio benévolo desea escuchar. Lo emprende jugando con los cuatro elementos que, según los presocráticos, componían el universo, reflejados en Frómista. Frómista es Tierra de Campos «infinita, pura, sin montes ni barrancos»; Frómista es agua: el Canal de Castilla, surco de fertilidad y progreso; Frómista es aire: los muchos valores de orden espiritual y cultural; Frómista es fuego: símbolo de la fe. Un fuego que alumbra en tres antorchas: San Telmo, el Milagro y la Virgen del Otero.

El capítulo tercero «Un milagro para una villa» recoge una conferencia que tuvo en Frómista el 13 de abril de 2002. Completa los datos de un trabajo anterior publicado en la revista XX Siglos (Revuelta González, 1993). El milagro sucede en el cambio de época, cuando la Edad Media entra en el Renacimiento. Palencia pasaba por un momento de esplendor, sobre todo cultural y Frómista era por entonces una villa próspera. El hecho en síntesis es: un labrador feligrés de la parroquia de San Martín Pedro Fernández era mayordomo del hospital de la parroquia. El hospital sufrió un incendio. El mayordomo pidió dinero prestado a un judío, prometiendo pagarle la deuda en un plazo determinado. Al no pagar la deuda en el plazo señalado, el judío acudió a la justicia eclesiástica, la cual dictó excomunión contra Pedro. Éste buscó dinero por otros medios y pagó al judío. Poco tiempo después Pedro enfermó con peligro de muerte, llamó al sacerdote, se confesó y le pidió el Viático.

El día de Santa Catalina, 25 de noviembre de 1453, el cura de la parroquia sale a llevar el Viático al enfermo, seguido de mucha gente porque era domingo. Cuando el sacerdote se dispone a darle la comunión, la sagrada forma quedó tan adherida a la patena de plata, que fue imposible despegarla. Todos quedaron admirados. El sacerdote le pregunta en secreto al enfermo si había dejado de confesar algún pecado. El enfermo le dijo que no. Le preguntó si estaba excomulgado. El enfermo le dijo que había incurrido en excomunión por no devolver el dinero al judío en el plazo convenido, pero que pensó que había quedado en paz al haberlo al fin devuelto. El cura lo absolvió y le administró el Viático con otra forma, pues la primera siguió pegada a la patena.

Manuel Revuelta habla sobre el contexto histórico del milagro y relata, ampliándolo, lo que había escrito en el artículo de Siglo XXI. El milagro fue 
tratado por notables historiadores. El Arcediano de Alcor Alonso Fernández de Madrid, narra en Silva Palentina cómo él había visto con sus ojos que todavía el Santo Sacramento está pegado a la patena. En Viaje Santo de 1572, Ambrosio de Morales relata el gran misterio del Santísimo Sacramento que se ve en Frómista. Por las mismas fechas Gonzalo de Illescas escribe en su Historia Pontifical sobre el milagro del Santísimo Sacramento. Fray Luis de Granada acude al «milagro» de Frómista en su Introducción al símbolo de la $\mathrm{Fe}$ para demostrar la excelencia de la fe y religión cristina. El ilustrado Gaspar Melchor de Jovellanos deja constancia en su Diario de su escepticismo ante «el cuento» del Milagro de Frómista.

$\mathrm{Al}$ hablar de las interpretaciones apologéticas del milagro, Manuel Revuelta historiador abre su introducción con las anfibologías de este párrafo, que nos deja algo en suspenso: «Por eso no es raro que teólogos, predicadores y escritores eclesiásticos esmalten sus sermones y tratados dogmáticos con la narración de hechos milagrosos que, a manera de ejemplos, conforman y amenizan la doctrina. Eran narraciones que encontraban gran eco en el pueblo sencillo. Se contaban de boca en boca y de generación en generación. Se recargaban con leyendas y se cantaban en romances. El lugar donde había sucedido el prodigio se convertía a menudo en santuario, con fiestas y cultos propios, que atraía a los peregrinos y fomentaba la creación de obras artísticas o joyas de orfebrería. El milagro se convertía en teología y en religiosidad popular. Prescindiendo del fundamento histórico de cada milagro, el recuerdo de los sucesos singulares y la veneración del pueblo manifiestan la fe de la Iglesia en el Sacramento del Cuerpo y de la Sangre del Señor» (Revuelta González, 2010).

Población está en un alto. Así encabeza Manuel Revuelta los capítulos cuarto, quinto y sexto que dedica a su villa natal. En el capítulo cuarto: "Cuatro momentos importantes en la historia de Población de Campos», resume en el primero lo poco que puede afirmarse y colegirse de los orígenes de Población (pp. 67-71); en el segundo, también en apretado resumen, expone lo que fue señorío de la Orden de Malta (pp. 71-76); en el tercer momento lanza una hipótesis de trabajo sobre un personaje de Castilla la Vieja que formaba parte del primer viaje de Colón, Pero Gutiérrez, repostero de estrados del rey. Él fue quien avisó tierra a la vista. A él le encargó el Almirante ir a pedir auxilio al cacique de la Española, Guacanagari, cuando la carabela Santa María encalló. Lo dejó al mando de la fortaleza La Navidad el 2 de enero de 1493 en la que quedaron 39 hombres que no regresaron a España. La hipótesis, apoyada solo en indicios es: si este personaje sería natural de Población de Campos (pp. 76-78). El cuarto momento nos presenta la reconstrucción de la iglesia parroquial de Santa María Magdalena en el siglo XVIII. 
Hace primero una presentación del pueblo en los años de 1749 a 1757, en los que se reconstruye la iglesia. Población era un pueblo pobre en recursos y en vecinos, que no llegaban al millar. En la nueva iglesia se colocó el gran retablo anterior (pp. 78-82).

Podríamos decir que el capítulo quinto es el corazón del libro. Se titula «Mensajes de arte y fe a orillas del Ucieza». El autor lo introduce con estas palabras: «Este capítulo se ha formado con cinco artículos breves, llenos de vivencias y recuerdos. El artículo dedicado a la ermita de San Miguel ha rescatado, en su primera parte, el ejercicio que escribí de niño sobre la entonces ruinosa ermita. Al encontrarlo años más tarde, entre viejos papeles que guardaba mi madre, añadí el comentario que se reproduce» (Revuelta González, 2010, p. 83).

Se trata de una composición escrita a los 15 años, en la que el autor lamenta las ruinas de la ermita de San Miguel ante la indiferencia y el olvido de la gente. El autor rescata y comenta la composición en su edad madura, para agradecer que ahora la ermita haya sido restaurada y hace al lector confidente de una experiencia íntima de su biografía: que en ella recién restaurada él celebró la eucaristía, recién ordenado sacerdote, en el año 1966, «acompañado de mis padres, mi abuela Julia, tíos, primos y algunos amigos» (Revuelta González, 2010, p. 87).

Todo el capítulo está ensamblado con piezas ocasionales escritas en estilo coloquial, exhortativo, en momentos lírico. La pieza «La ermita de la Virgen del Socorro, la voz de las piedras» (pp. 88-90) fue escrita para una Hoja parroquial. Es un resumen concentrado del artículo que publicó, en 1973, en PITTM. «Sólo que aquí, las piedras hablan, acarician, en su suave penumbra la Reina Madre nos presenta al Salvador del mundo». La brevísima pieza «La Patrona del pueblo» es un fervorín que había publicado en una revista popular, El Promotor. El siguiente apartado: «El "Ecce Homo” de Población» (pp. 91-104) es una pieza publicada originariamente en la revista El Reino de Cristo, en 1991. Es un estudio ejemplar de breve exposición histórica y de interpretación teológica: «esta imagen de Cristo rezuma aquella locura de la cruz que contagiaba a los santos» (Revuelta González, 2010, p. 90). El apartado quinto: «El altar mayor: retablo barroco y catequesis católica» es un estudio en tres secciones hecho con ocasión de la restauración, en 2007, del retablo mayor de la iglesia parroquial Santa María Magdalena de Población. Un magnífico retablo barroco de mediados del siglo XVIII, que había quedado dañado, en su policromía y dorado, en el incendio de abril de 1985. En la financiación de la obra tuvo su parte principal el legado de doña Gregoria González Nogal, madre del autor. La primera sección (pp. 95-98) es una descripción del retablo, la segunda (pp. 99-101) es un breve estudio de las fases 
de construcción del retablo, y la tercera (pp. 102-104) una interpretación catequética en la clave del Credo: fe en Dios Padre - fe en Jesucristo- fe en el Espíritu Santo - fe en la Iglesia Católica - fe en la comunión de los santos. Un modelo de interpretación correcto, no sin cierto malacate.

No puede resistirse Manuel Revuelta a incluir en este libro, que es como una síntesis de lo que ha escrito sobre Palencia, una comunicación publicada en las Actas de Primer simposio de la Orden de San Juan en España, editadas en Toledo en 2003: «La bailía de Población o de las nueve villas», un resumen actualizado del artículo que publicó en PITTM de 1972.

El cuarto pueblo del Camino de Santiago que reseña Manuel es Revenga de Campos, a 4 km al este de Población. Lo nombra «Revenga, alivio de caminantes», y a él dedica el capítulo séptimo del libro: «El paso de dos grandes personajes históricos por Revenga» (pp. 115-119). Se vale de un breve artículo que había publicado, en el año 2002 en la revista el Fardel, que se edita en Revenga, al que añade algunos datos. El primer personaje en pasar por Revenga es Carlos V cuando solo era príncipe Carlos con 17 años y venía a España, desde su Flandes natal, a tomar posesión de las coronas de Castilla y Aragón. Un viaje accidentado por mar obligó a la comitiva a desembarcar en el puerto de Tazones en Asturias el 19 de septiembre de 1517, y no en el puerto de Santander al que se dirigían. El príncipe tenía prisa por encontrarse en Tordesillas con su madre, Juana la Loca, y siguió su ruta por caminos poco frecuentados. Esto explicaría su paso por Revenga, donde su hermana Leonor y él pernoctaron del 30 al 31 de octubre. Su cronista Lorenzo Vidal deja constancia de una estancia agradable en Revenga.

Don Gaspar Melchor de Jovellanos pasa por Revenga de camino hacia Asturias en la tarde del 3 de junio de 1795. Se detiene en el pueblo. En su Diario apunta: «Revenga. Detención para evitar el sol. Iglesia pequeña muy antigua, con muchas malas renovaciones. Tratan de otra nueva y se hacen los planos por un arquitecto de Palencia». La nueva iglesia parroquial de San Lorenzo se terminaría de construir en 1797.

En la segunda parte del libro hay algo de relleno — «otros afanes». Este aspecto tiene el capítulo octavo: «Iglesia, religiosidad tradicional y disidencias» (pp. 123-140). Es un fascículo (Revuelta 1998), en el que nada nuevo dice el autor en la primera parte que no haya publicado ya con más detenimiento y solvencia en otros momentos. Sólo en la página en que habla de la guerra civil y de los fervores de la postguerra apunta a unos escuetos y exactos datos. Lo mismo hace al hablar del Concilio Vaticano II y la revisión y renovación de la Iglesia palentina. En la segunda parte: «Religiosidad popular, devociones y disidencias» está muy bien resumido lo también publicado antes por él. 
Lo contrario resultan el capítulo noveno: «Los orígenes del sindicalismo católico agrario en Palencia» (pp. 141-167), resultado de una conferencia que el autor pronunció en la Diputación de Palencia en mayo de 2003, y el capítulo décimo, dedicado al gran propagandista de los sindicatos en España, Antonio Monedero (pp. 169-189). En otros trabajos anteriores ha dado cuenta Manuel Revuelta de la importancia del clero y personalidades católicas en el movimiento social católico agrario en Palencia. En estos dos recorre, en el primero, las etapas del desarrollo de los llamados Círculos de obreros, que en 1906 ya habían celebrado la asamblea de las Corporaciones Católicas Obreras del norte de España. En los años siguientes se desarrolla cada vez más la acción social católica, y en 1912 se contaban en la provincia más de treinta sindicatos católicos, la mayoría mixtos, formados por propietarios, colonos y jornaleros. El 5 de mayo de 1912 se celebra en Palencia el gran mitin fundacional de la Federación Agraria Palentina, en el que Antonio Monedero fue elegido presidente de la Federación. Fue el punto de arranque del sindicalismo católico agrario en Palencia y en toda España.

En la labor de organizar de la Federación Agraria, Ángel Herrera puso en contacto a Monedero con el jesuita Sisinio Nevares, profesor de la Universidad de Deusto, que llevaba tres años dedicándose, en los veranos, a recorrer los pueblos de la Tierra de Campos para convencer a los campesinos que formaran sindicatos agrícolas. En la gran campaña de propaganda para dar a conocer la Federación, Nevares, y a su lado Monedero, son los organizadores y principales oradores. En los meses de septiembre y octubre recorren los pueblos al norte de la Tierra de Campos. La respuesta fue masiva. Quedaron fundadas 40 asociaciones agrarias para 235 pueblos y unos 8.000 agricultores. En 1913 la Federación Católico Agraria de Palencia agrupaba 54 sindicatos en los que tenía al menos 15.000 familias. Siguieron adscribiéndose nuevos sindicatos. Monedero y Nevares se convierten en líderes de alcance nacional.

El largo capítulo se cierra con este colofón: «El sindicalismo católico agrario produjo, durante tres décadas difíciles, un inmenso bien a millares de familias campesinas. A parte de las ventajas materiales, fomentó en la clase campesina valores perennes: la unidad profesional, la conciencia de la propia dignidad y los ideales cristianos de fraternidad y de justicia» (Revuelta 2010, p. 167).

Antonio Monedero pertenecía a una estirpe aristócrata afincada en el Cerrato palentino, donde era dueña de grandes posesiones. Nacido en Dueñas el año 1872, se doctora en Derecho en Valladolid. Viaja por Suiza, Alemania, Bélgica y Francia, donde se casó. Vuelve a Dueñas dispuesto a aplicar a su gran propiedad del Aguachal las técnicas que había conocido 
en estos viajes. Además de experimentar como ganadero y agricultor, se convierte en el difusor de las técnicas agropecuarias, con dotes de pedagogo y buen escritor.

En la noche del 20 al 21 de enero de 1913, un incendio destruyó prácticamente su casa-palacio de Dueñas, desapareciendo su biblioteca y gran parte de los muebles y objetos de arte. Se perdieron la cosecha de trigo de las paneras y el vino de las bodegas. Monedero interpretó estos desastres como una llamada del Señor al despego de las cosas propias para ocuparse más de las de Dios. Arrienda las fincas y se dedica en cuerpo y alma a promocionar un sindicalismo confesional, sindicalismo mixto, sistema más adaptado al campo como alternativa al socialismo y liberalismo. En 1915 es nombrado presidente de la Confederación Católico-Agraria de Castilla y León con Sisinio Nevares de consiliario. Fue presidente de la Confederación Católico-Agraria de 1917 a 1919. Entre abril y septiembre de 1919 fue Director de Agricultura. Dimite en noviembre de 1921, al notar que en el ministerio se daba preferencia a las cámaras agrícolas de los patronos. De 1922 a 1940 se dedicará a la propaganda católico-agraria. Crea la Liga Nacional de Campesinos en 1923. Mostró complacencia con la Dictadura y posibilismo con la República. Apoyó al Movimiento Nacional de 1936. Pronto se desengañó. En enero de 1940 el nuevo Régimen creaba el sindicato único falangista. Se retira a su casa de Dueñas, donde muere el 23 de octubre de 1940.

Don Antonio Monedero siempre puso la llamada a la acción social por encima de sus riquezas, comodidades e intereses. Dedicó su vida a la mejora material y moral de las gentes del campo, prefiriendo siempre a los más pobres. Cristiano ejemplar, se puede calificar de palentino universal.

Cierra Manuel Revuelta esta segunda parte del libro con el texto de una conferencia que pronunció en Aguilar de Campoo en junio de 2006: «El arte perdido y hallado en Palencia» (pp. 191-207). Prácticamente, todo lo que dice aquí lo había expuesto ya en el artículo de 1999 publicado en PITTM (Revuelta 199, pp. 359-384). Aquí añade la última sección: «Los contrastes del siglo XX», dando cuenta de las principales obras perdidas para Palencia que se encuentran en museos extranjeros o en lugares dentro de España, y del arte recuperado y salvado, sea por hallazgos inesperados o porque en la sociedad se ha recuperado el sentimiento estético que capta el valor de la obra artística en sus múltiples expresiones. En 15 jalones cronológicos resume el autor la progresión de la estima y cuidado del tesoro artístico de Palencia en el siglo XX. El último escalón nos lleva a dos hitos: la Villa Romana de la Olmeda y el monasterio de Santa María la Real. 


\section{$* * *$}

La obra de Manuel Revuelta dedicada a Palencia está constituida prácticamente toda por artículos elaborados en los intersticios de tiempo que le dejaba la dedicación a las obras que ocupaban sus horas de trabajo, o debido a compromisos ocasionales. Queda, sin embargo, perfectamente integrada en su obra mayor, por su rigor en la ponderación del material histórico que trata.

Manuel Revuelta fue un historiador que desarrolló su labor docente e investigadora de manera consciente como sacerdote jesuita. Toda su obra escrita sobre la historia de la Iglesia se distingue de una mera crónica en que, para él, la Iglesia es el ámbito vital de millones de seres humanos que buscan convivir y compartir con todos porque, para ellos, la humanidad está bajo la mirada providente de Dios. Es la pauta de lectura que debe seguirse en estos trabajos dedicados a Palencia. En siete de estos trabajos se ocupa de la historia de la Iglesia en Palencia en el siglo XIX y primer decenio del siglo XX, la época más transitada por él en su labor de historiador, y en la que ha dado muestras de saber poner al lector en condiciones de hacerse y hacer preguntas.

Es lo que deja bien claro él, en el libro que publica en 2010, echando una mirada retrospectiva a toda su obra, cuando está a punto de cumplir los 75 años de una vida dedicada a la investigación y enseñanza de la historia.

\section{REFERENCIAS}

Pérez García, A. (2019). P. Manuel Revuelta González, S.J. Miscelánea Comillas 77, 250.

Revuelta González M. (1971). La bailía de Población de la Orden de San Juan de Jerusalén. Publicaciones de la Institución Tello Téllez de Meneses (PITTM), 32, 249-277.

Revuelta, M. (1973). Noticias históricas de la ermita de Nuestra Señora del Socorro de Población de Campos, PITTM 34, 249-277.

Revuelta, M. (1979). La desamortización eclesiástica en Aguilar de Campoo. PITTM 43, 173-208.

Revuelta, M. (1987). Informe del obispo de Palencia Don Juan Lozano a la Santa Sede sobre el estado de la diócesis. En: Actas del I Congreso de Historia de Palencia III, Palencia. Diputación Provincial, 457-472.

Revuelta, M. (1988). La diócesis de Palencia durante el pontificado de don Enrique Almaraz (1893-1907). En: Actas del II Congreso de Historia de Palencia, II. II. Palencia. Diputación Provincial, 605-650.

Revuelta, M. (1993). El milagro eucarístico de Frómista, XX Siglos, IV (15), 62-73. 
Revuelta, M. (1994), Origen, ocaso y renovación de los conventos palentinos. PITTM, 63, 49-91.

Revuelta, M. (1995), Iglesia y sociedad en Palencia durante el reinado de Alfonso XIII. En: Actas del III Congreso de Historia de Palencia III. Palencia. Diputación Provincial, 323-385.

Revuelta, M. (1998). Iglesia, religiosidad tradicional y disidencias. En: García Colmenares, P., Moreno Lázaro, J. y Sánchez García, I., Historia de Palencia: siglos XIX y XX (289-300). Palencia. El Norte de Castilla.

Revuelta, M. (1999). La recuperación artística en Palencia. PITTM, núm. 70, 359-284.

Revuelta, M. (2001). Finanzas y poesía. México y Palencia a través de la familia Mier y Pesado. PITTM, núm. 72, 5-42.

Revuelta, M. (2007). El Padre Nicolás de Bobadilla, cofundador de la Compañía de Jesús y misionero de Europa. Otero, núm. 9, 73-84.

Revuelta, M. (2008). Aspectos religiosos en la Guerra de la Independencia y su repercusión en Palencia. PITTM 79, 155-178.

Revuelta, M. (2010). Historia y espíritu en tierras palentinas. Palencia. Diputación de Palencia.

Ruiz, G. (1987). Encuentro con Goyo. Palencia. Caja de Ahorros y Monte de Piedad, D.L. 